\title{
Energy-Efficient Rehabilitation of Multifamily Buildings in the Midwest
}

\section{SUMMARY}

This report addresses the opportunities available to make multifamily housing more affordable by using energy efficiency practices in housing rehabilitation. Use of the energy conservation measures discussed in this report enables developers of multifamily housing to substantially reduce annual energy costs. The reduction in natural gas usage was found to be approximately 10 Btu per square foot per heating degree-day. For an average Chicago heating season with 6,455 heating degree-days, an apartment of 1,100 $\mathrm{tt}^{2}$ would save about 710 therms of natural gas and lower its gas energy costs by approximately $\$ 355$. This dollar savings exceeds the costs of one month of affordable housing for a family earning $\$ 14,000$ per year. The energy conservation measures also improve the typical net cash available per dwelling unit to the owner of the building by more than $\$ 250$ per year after debt service.

The study focuses on a number of Chicago multifamily buildings. The buildings were examined to compare energy efficiency measures that are commonly found in multifamily building rehabilitation with the high-energy-efficiency (HE) techniques that are currently available to community developers but are often unused. The HE measures include R-43 insulation in attics, R-19 insulation in exterior walls, lowemissivity coatings on windows, air infiltration sealing, and HE heating systems.

The report describes the HE features and their potential benefits for making housing more affordable. It also describes the factors influencing acceptance. This report makes recommendations for expanding cost-effective energy conservation in the multifamily building sector. Among the recommendations are:

- Expand HE rehab and retrofit techniques to multifamily building rehabs in which demolition of the interior structures is not required (moderate rehabs) or buildings are not vacant (e.g., weatherization upgrades); and

- Expand research into the special opportunities for incorporating energy conservation in low-income communities. 
This report can be accessed directly on the Internet with MOSAIC by setting the URL to: http://www.dis.anl.gov/ee/cgi-bin/rehab_doc/rehab_title.html

Other information on energy efficiency is accessible at:

http://www.dis.anl.gov/ee/ee.html 


\section{DISCLAIMER}

This report was prepared as an account of work sponsored by an agency of the United States Government. Neither the United States Government nor any agency thereof, nor any of their employees, make any warranty, express or implied, or assumes any legal liability or responsibility for the accuracy, completeness, or usefulness of any information, apparatus, product, or process disclosed, or represents that its use would not infringe privately owned rights. Reference herein to any specific commercial product, process, or service by trade name, trademark, manufacturer, or otherwise does not necessarily constitute or imply its endorsement, recommendation, or favoring by the United States Government or any agency thereof. The views and opinions of authors expressed herein do not necessarily state or reflect those of the United States Government or any agency thereof. 


\section{Energy-Efficient Rehabilitation of Multifamily Buildings in the Midwest}

by J.T. Katrakis, P.A. Knight, and J.D. Cavallo

Policy and Economic Analysis Group,

Decision and Information Sciences Division,

Argonne National Laboratory, 9700 South Cass Avenue, Argonne, Illinois 60439

September 1994

Work sponsored by United States Department of Energy,

Assistant Secretary for Energy Efficiency and Renewable Energy,

Office of Building Technologies, Existing Buildings Research Program 


\section{DISCLAIMER}

Portions of this document may be illegible in electronic image products. Images are produced from the best available original document. 


\section{CONTENTS}

ACKNOWLEDGMENTS $\ldots \ldots \ldots \ldots \ldots \ldots \ldots \ldots \ldots \ldots \ldots \ldots \ldots \ldots$ vi

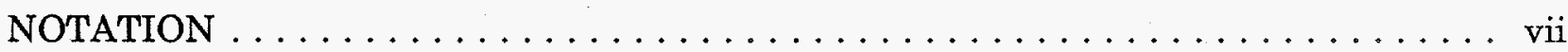

1 INTRODUCTION $\ldots \ldots \ldots \ldots \ldots \ldots \ldots \ldots \ldots \ldots \ldots \ldots \ldots \ldots \ldots \ldots \ldots \ldots \ldots$

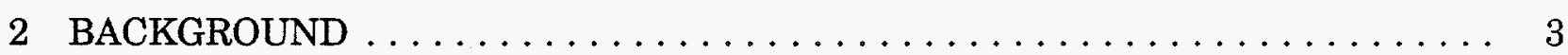

2.1 The Need for Affordable Housing $\ldots \ldots \ldots \ldots \ldots \ldots \ldots \ldots \ldots$

2.2 The Need for Better Housing $\ldots \ldots \ldots \ldots \ldots \ldots \ldots \ldots \ldots \ldots \ldots \ldots \ldots \ldots \ldots \ldots$

2.3 Potential Improvements $\ldots \ldots \ldots \ldots \ldots \ldots \ldots \ldots \ldots \ldots \ldots \ldots \ldots \ldots \ldots$

3 ENERGY EFFICIENCY AND AFFORDABLE HOUSING $\ldots \ldots \ldots \ldots \ldots \ldots$

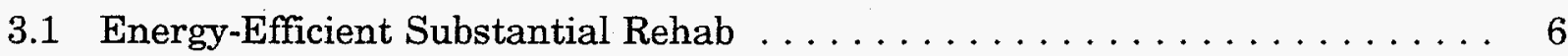

3.2 Energy-Efficient Moderate Rehab . . . . . . . . . . . . . . . . 7

3.3 Energy Efficiency Retrofit Programs $\ldots \ldots \ldots \ldots \ldots \ldots \ldots . \ldots$

4 ENERGY COSTS IN EXISTING LOW-INCOME HOUSING $\ldots \ldots \ldots \ldots \ldots \ldots$

5 COMPARING HE AND TYPICAL REHAB COMPONENTS . . . . . . . . . . 13

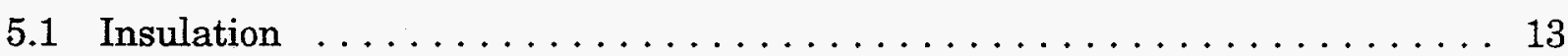

5.1 .1 Exterior Wall Insulation $\ldots \ldots \ldots \ldots \ldots \ldots \ldots \ldots \ldots \ldots \ldots \ldots$

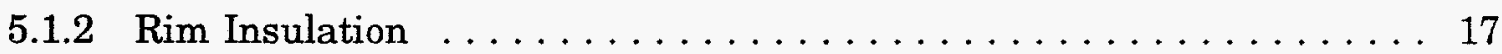

5.1 .3 Interior Masonry Bearing Wall $\ldots \ldots \ldots \ldots \ldots \ldots \ldots \ldots \ldots$

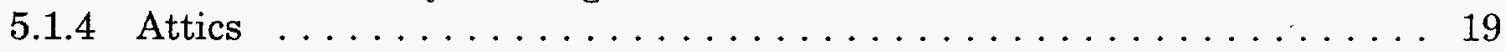

5.1 .5 Basements . . . . . . . . . . . . . . . . . . . . . . 19

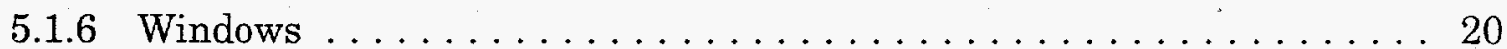

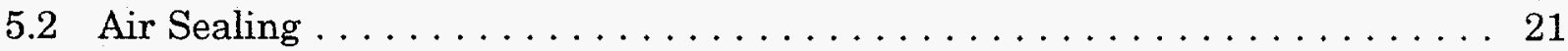

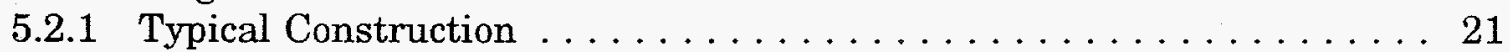

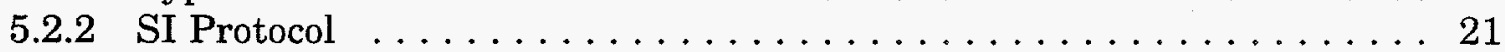

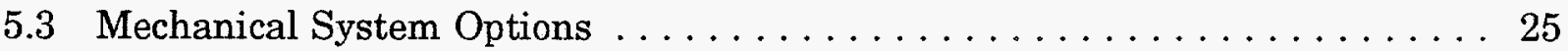

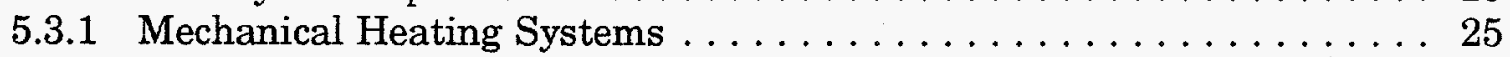

5.3 .2 Mechanical Ventilation Systems $\ldots \ldots \ldots \ldots \ldots \ldots \ldots \ldots \ldots$

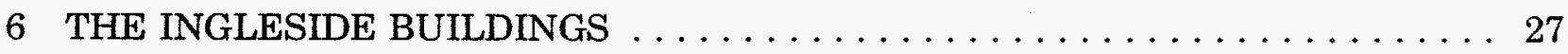

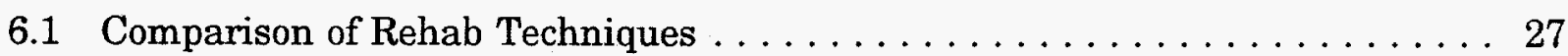

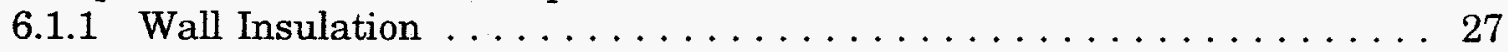

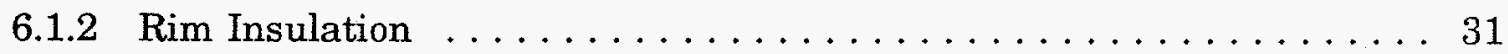

6.1.3 Interior Masonry Bearing Wall $\ldots \ldots \ldots \ldots \ldots \ldots \ldots \ldots \ldots \ldots \ldots \ldots \ldots \ldots$

6.1 .4 Attic Insulation . . . . . . . . . . . . . . . . . . . . 34

6.1.5 Insulation of Ground-Floor Slab $\ldots \ldots \ldots \ldots \ldots \ldots \ldots \ldots \ldots \ldots \ldots$

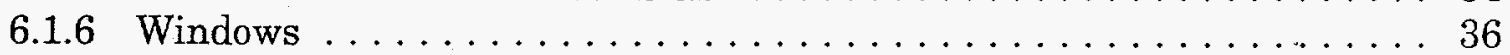

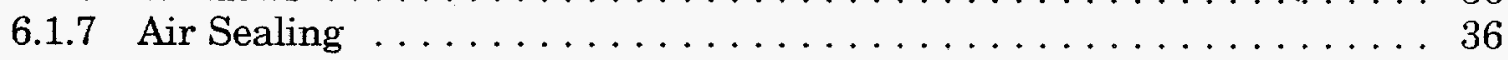

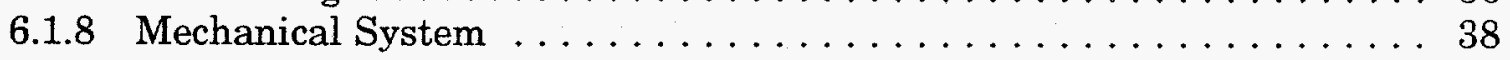




\section{CONTENTS (Cont.)}

6.2 Performance Comparison $\ldots \ldots \ldots \ldots \ldots \ldots \ldots \ldots \ldots \ldots \ldots \ldots \ldots \ldots$

7 THE COVENANT BUILDING $\ldots \ldots \ldots \ldots \ldots \ldots \ldots \ldots \ldots \ldots \ldots \ldots \ldots \ldots \ldots$

7.1 Method of Analysis . . . . . . . . . . . . . . . . . . 40

7.2 Energy Usage . . . . . . . . . . . . . . . . . . . . . . . 40

7.3 Energy Cost .............................. 42

7.4 Construction Costs and Cost-Effectiveness . . . . . . . . . . . 45

7.5 Infiltration Measurements . . . . . . . . . . . . . . . . 45

8 CONCLUSIONS AND RECOMMENDATIONS $\ldots \ldots \ldots \ldots \ldots \ldots \ldots$

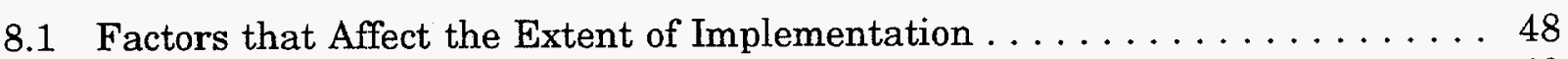

8.1.1 Developers and Building Managers $\ldots \ldots \ldots \ldots \ldots \ldots \ldots \ldots$

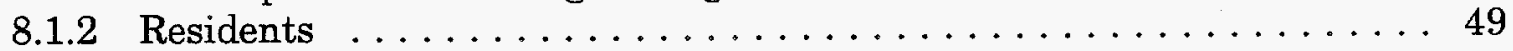

8.1 .3 Financiers . . . . . . . . . . . . . . . . . . . 49

8.1.4 Design Consultants and Project Managers . . . . . . . . . . . 50

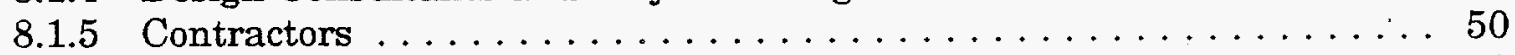

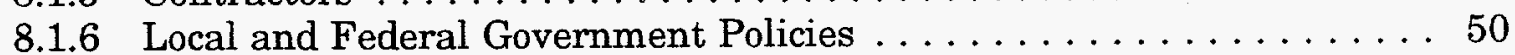

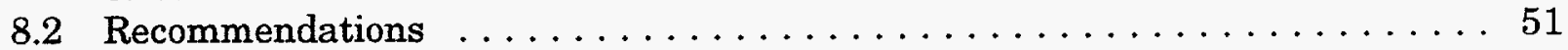

8.2.1 Program Development . . . . . . . . . . . . . . . . 51

8.2.2 Technical Research, Development, and Demonstration ........ 52

9 REFERENCES . . . . . . . . . . . . . . . . . . . . . 56

\section{TABLES}

1 Performance of Rehabbed Multifamily Buildings $\ldots \ldots \ldots \ldots \ldots \ldots \ldots$

2 Energy and Housing Costs in Operating Low-Income Housing . . . . . . . . 11

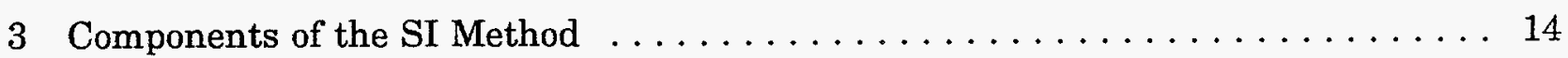

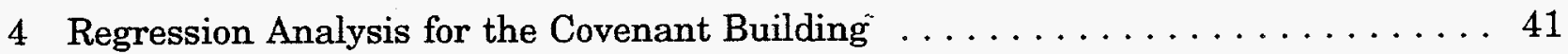

5 Modeled Distribution of Energy Costs in an SI Rehab .............. 43

6 Modeled Distribution of Energy Costs in a Conventional Rehab ........... 44

7 Incremental First Cost per Apartment and Building $\ldots \ldots \ldots \ldots \ldots \ldots$

8 Cash Flow for SI, Master-Metered Rehab: Covenant Community Development Corporation Six-Unit Building $\ldots \ldots \ldots \ldots \ldots \ldots$

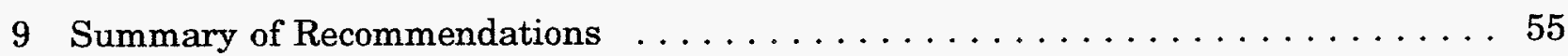




\section{FIGURES}

1 Typical Wall Section in SI Building $\ldots \ldots \ldots \ldots \ldots \ldots \ldots \ldots \ldots$

2 Typical Exterior Wall with Interior Partition $\ldots \ldots \ldots \ldots \ldots \ldots$

3 Typical Exterior Wall with Existing Bearing Wall . . . . . . . . . . . . . 19

4 Existing Pulley Well Packed with Insulation . . . . . . . . . . . . . 23

5 Window Head and Sill Insulated and Sealed to the Window Frame . . . . . . . 24

6 Wall Section Used in the $4737 \mathrm{~S}$. Ingleside Building where Existing Plaster and Lath Remained . . . . . . . . . . . . . . . . . 29

7 Wall Section Used in the $4737 \mathrm{~S}$. Ingleside Building where Existing Plaster and Lath Were Removed $\ldots \ldots \ldots \ldots \ldots \ldots$

8 Wall Section Used in the 4746 S. Ingleside Building $\ldots \ldots \ldots \ldots \ldots$

9 Plan View of "Fin" Wall and New Interior Partition Wall Used in the $4737 \mathrm{~S}$. Ingleside Building $\ldots \ldots \ldots \ldots \ldots \ldots \ldots$

10 Plan View of "Fin" Wall and New Interior Partition Wall Used in the $4746 \mathrm{~S}$. Ingleside Building $\ldots \ldots \ldots \ldots \ldots \ldots \ldots$ 


\section{ACKNOWLEDGMENTS}

The research for this report was part of an interdepartmental effort - the U.S. Department of Energy - U.S. Department of Housing and Urban Development (DOEHUD) Initiative. The authors acknowledge and greatly appreciate the support provided by the Existing Buildings Research Program of DOE and, in particular, the support of Ernest Freeman. We also thank Robert Groberg of HUD for his insights and encouragement. We have benefited throughout this project from the assistance and guidance of William Mixon and J. Michael MacDonald of Oak Ridge National Laboratory, Richard Diamond and Helmut Feustel of Lawrence Berkeley Laboratory, and Henry Kurth and Maureen Davlin of the nlinois Department of Energy and Natural Resources. We would also like to acknowledge the insights provided by members of the staff at the Energy Resources Center of the University of Illinois at Chicago, Laura Skup Gomez of Argonne National Laboratory, Raymond Lau of the Center for Neighborhood Technology, John Porterfield of Covenant Community Development Corporation, and Yvonne Thomas of the Kenwood Oakland Development Corporation. All results, errors, and opinions in this paper are solely those of the authors and should not reflect on DOE or other members of the national laboratory system.

This report has benefited from the keen eye and editorial expertise of Margy Ortigara; the authors are grateful for her assistance. We also owe debts of gratitude to Bob Baker and Jim Zawada for including this report on DOE's Energy Efficiency and Renewable Energy Network (EREN). We hope that in the future many such reports will be freely available to community developers through the Internet. 


\section{NOTATION}

The following is a list of the acronyms, initialisms, and abbreviations (including units of measure) used in this document.

\section{ACRONYMS, INITIALISMS, AND ABBREVIATIONS}

ADA

AFUE

ANL

ASHRAE

CESF

ENR

HE

HUD

low-E

PCLF

SI

WAP
Airtight Drywall Approach

Average Fuel Utilization Efficiency

Argonne National Laboratory

American Society of Heating, Refrigerating, and

Air Conditioning Engineers

Chicago Energy Savers Fund

Illinois Department of Energy and Natural Resources

high-energy-efficiency

U.S. Department of Housing and Urban Development

low-emissivity

Peoples Conservation Loan Fund

Super Insulation

Weatherization Assistance Program

\section{UNITS OF MEASURE}

$\mathrm{Btu} / \mathrm{ft}^{2} /$ degree-day $\quad$ British thermal unit(s) per square foot per heating degree-day

${ }^{\circ} \mathrm{F}$

$\mathrm{ft}$

$\mathrm{ft}^{2}$

$\mathrm{ft}^{3}$

$\mathrm{h}$

in.

$\mathrm{lb}$

$\min$

$\mathrm{yr}$

\section{degree(s) Fahrenheit}

foot (feet)

square foot (feet)

cubic foot (feet)

hour(s)

inch(es)

pound(s)

minute(s)

year(s) 


\title{
ENERGY-EFFICIENT REHABILITATION OF MULTIFAMILY BUILDINGS IN THE MIDWEST
}

by

\author{
J.T. Katrakis, P.A. Knight, and J.D. Cavallo
}

\section{INTRODUCTION}

This report presents a survey of the feasibility and effectiveness of incorporating high levels of energy efficiency into the rehabilitation of multifamily housing. The evaluation is intended to discern the nature and extent of the benefits that result from the high-energyefficiency (HE) features, explore their effectiveness in reducing the costs of low-income housing, and assess what is necessary to promote their appropriate and widespread application.

The survey focused on multifamily buildings that were rehabilitated (i.e., "rehabbed") in a manner that includes the HE techniques developed by the Illinois Department of Energy and Natural Resources (ENR) and the Energy Resource Center at the University of Illinois at Chicago. ENR refers to its package of measures as the "Super Insulation" (SI) method. In this report, we also refer to these measures as part of a comprehensive HE practice for multifamily housing that includes $\mathrm{HE}$ water heating, ventilation, and appliances and lighting for the residents.

The report first provides background on the extent of the problem faced by lowerincome residents living in apartments with high energy costs and on the significant opportunities available to incorporate long-term and substantial energy savings into these buildings. The buildings are primarily the three-story walk-up, multifamily buildings of masonry construction from the World War I era that are so common in the northern Midwest.

ENR's SI method is described and contrasted with the range of conventional rehab practices in the Chicago area. The intent is to provide an overview of how these HE features are applied to these buildings.

The performance of buildings rehabbed with ENR's method is contrasted with that of buildings that received conventional rehab. The performance evaluation compares energy usage. It also compares the effect on the energy costs borne by the building owner and the resident and the effect on construction costs and debt service. The economic and environmental impacts of the HE measures are described in terms of the various participants in the affordable housing industry, including the developers, residents, housing managers and owners, financiers, contractors, and government agencies.

Next, the barriers to widespread and effective dissemination of these techniques are outlined. These barriers are identified and described in terms of the various participants in the housing industry. 
Finally, conclusions and recommendations are presented in an effort to develop appropriate policies, enhance existing programs, and identify new research and development and technology transfer activities that will explore the full potential of HE technologies to make housing more affordable. 


\section{BACKGROUND}

\subsection{THE NEED FOR AFFORDABLE HOUSING}

The U.S. Department of Housing and Urban Development (HUD) defines affordable housing as costing no more than $30 \%$ of an occupant's income, including energy costs. Yet in $1989,56 \%$ of poor renters (or 3.5 million households) spent at least $50 \%$ of their income on rent and utilities. More than $80 \%$ of poor renter households ( 5.1 million) spent at least $30 \%$ of their income on rent and utilities. This is in sharp contrast to a middle-income family with an annual income of $\$ 50,000$ that spends less than $15 \%$ of its income on rent and utilities (Lazere et al. 1991).

The past 24 years have seen a growing shortage of affordable multifamily housing in this country. In 1970, a surplus of affordable housing existed: the 6.8 million rental units with housing costs (rent and utilities) of less than $\$ 250$ (in 1989 dollars) per month was 0.4 million greater than the 6.4 million low-income renters. By 1989, the number of low-cost (less than $\$ 250$ ) units had declined to 5.5 million, yet the number of poor renter families had increased to 9.6 million, or $12.5 \%$ of the total population. This shortfall of about 4.1 million housing units is distributed throughout the country. The Midwest accounts for about 1.1 million of the shortfall (Lazere et al. 1991).

The declining supply of low-cost multifamily housing is particularly burdensome to poor households that are below the poverty line (about $\$ 10,000$ income per year for a family of three in 1989). Poor households, referred to as "very-low-income" households by HUD, are those whose family income is $35 \%$ below the median income in their area. In 1989, about three-fifths of all poor households throughout the nation were renters.

In 1989, a little more than one-third of the poor renter households received housing assistance from the federal, state, or local government or lived in public housing. Yet between 1973 and 1989, the number of private market, or unsubsidized, housing dropped sharply by $41 \%$. This drop was caused by a number of factors, including the abandonment of deteriorated units, the upgrading of low-rent units into higher-priced units, the conversion to condominiums, and increases in energy costs.

Some recent trends have the potential to exacerbate the shortage of affordable lowincome housing. The conversion from HUD-assisted to private properties is accelerating. As the government contracts for subsidized housing end, the owners are freed to enhance the value and price of these properties and market their housing to higher-income residents. Recently, proposals have been renewed to eliminate the funding for the Low-Income Heating Assistance Program (LIHEAP), which provides direct utility bill subsidies for qualifying individuals. This program was initiated in 1981 after the oil-price shocks of the 1970s that drove up the price of home heating fuel. Federal funding for this program peaked in 1985 at $\$ 2.1$ billion and dropped below $\$ 1.5$ billion in recent years. In 1990-91, the United States had an estimated 1.125 million low-income households whose heat source was interrupted because of their inability to pay. Furthermore, it is estimated that only $23 \%$ of the 28 million 
Americans who meet the federal guidelines for energy assistance actually receive any aid (Horn 1994).

\subsection{THE NEED FOR BETTER HOUSING}

Not only is housing expensive for lower-income families, it is also deficient and overcrowded. Although in 1989 lower-income families accounted for $12.5 \%$ of all households in the nation, they occupied $24 \%$ of the units with severe physical problems, $36 \%$ of the units with holes in the floor, and $32 \%$ of the units lacking kitchen facilities such as a stove or a refrigerator. Where these appliances are available, they are typically older and inefficient and, therefore, costly to operate.

Lower-income families are also more than three times as likely as non-poor households to live in overcrowded conditions, that is, with more than one person per room. In 1989, approximately 1 million poor households lived in overcrowded conditions.

Because lower-income housing is older, it is more likely to be contaminated with lead and asbestos-laden materials. The lead issue has become especially important in recent years as local and state municipalities struggle to strike the right balance between mandating expensive investments in lead abatement and containment and maintaining the affordability of low-income multifamily housing.

Housing for lower-income people is more likely to have problems with providing adequate and safe heat, especially during colder weather. In these buildings, the residents are more likely to use their gas ranges or electric and gas space heaters to compensate for the insufficient heat from the building. Such excessive use of appliances is more likely to pose a fire hazard and degrade air quality. Contributing to the hazard are the likely substandard building wiring and perhaps older faulty appliances that are being used for other than their intended purposes.

\subsection{POTENTIAL IMPROVEMENTS}

Recent policy initiatives have the potential to address the needs for affordable and better housing. Tax credits are available for investments that result in more low-income housing. The National Affordable Housing Act of 1990 and its HOME Investment Partnership program provide local grants for designing and operating rental and home ownership programs. In particular, the act provides support to community-based nonprofit housing groups because they are playing a greater role in advocating and developing affordable housing.

In Chicago, these legislative initiatives coupled with the efforts of local housing groups and the city government have resulted in plans for investing more than $\$ 750$ million over the next five years to increase the number of affordable housing units for low-income families. This investment is intended to create new or substantially upgrade some 
17,700 units of housing. About $35 \%$ of this housing is for families earning less than $\$ 15,000$ per year, and two-thirds of this housing is for families earning less than $\$ 24,000$ per year. Therefore, in Chicago alone a significant opportunity exists to make substantial numbers of new and rehabbed housing units for lower-income families more affordable by designing them at the start for minimal energy costs. 


\section{ENERGY EFFICIENCY AND AFFORDABLE HOUSING}

Typically, affordable rents or mortgages are achieved by minimizing construction costs. Yet, in an effort to meet this goal, energy efficiency is often excluded. The result is housing that may have affordable rents or mortgages but unaffordable energy costs. Following is a review of recent and current efforts to incorporate energy efficiency into affordable low- and moderate-income housing. We have focused on Chicago's lower-income multifamily housing stock, which is typical of the lower-income multifamily housing throughout the Midwest. These buildings are three-story walk-up masonry structures that were built in the decades before and after World War I.

\subsection{ENERGY-EFFICIENT SUBSTANTIAL REHAB}

Beginning in 1988, ENR initiated the Multifamily Building Super Insulation Program. ENR, together with the Energy Resource Center at the University of Illinois in Chicago, has been working with Illinois nonprofit affordable housing developers to integrate energy-efficient building practices in multifamily building rehab. The objective of the program is to demonstrate that including energy-efficient building practices in multifamily building rehab actually lowers overall housing costs. ENR's approach provides both technical and financial assistance to developers.

Collectively, the energy-efficient building practices are referred to as SI. SI practices originally developed for new single-family home construction were modified by ENR for masonry buildings undergoing substantial or "gut" rehab. Gut rehab includes removing all the interior lath and plaster wall finishes as part of a total replacement of all building systems. Buildings that require gut rehab typically have been abandoned for a number of years and therefore have suffered damage from the elements and vandalism. Walls are beyond simple patching and painting, and all windows are missing or shattered and require replacement. Major portions of the heating system have been removed, and debris has entered the distribution piping. The intent of gut rehab is to use whatever is salvageable of the existing building structure and to completely replace all other building systems, thereby bringing a building up to today's standards in construction quality and building codes. ENR's SI package comprises the following HE techniques:

- High insulation levels,

- An emphasis on indoor air sealing and indoor air quality,

- HE heating and ventilation systems, and

- HE lighting.

The major focus of the SI approach is embodied in high insulation levels and the emphasis on indoor air sealing. These components have evolved from the original SI concepts developed for single-family housing by the Small Homes Council of the University of Illinois 
in Champaign-Urbana. They also are adaptations of the air-sealing methods such as the Airtight Drywall Approach (ADA). Indoor air quality is also an important consideration in the SI approach.

The SI approach has been applied with a wide range of heating system types. However, its performance to date has been most dramatic when it includes HE (rated Average Fuel Utilization Efficiency [AFUE] greater than 90\%) forced-air furnaces or individual combined heating systems consisting of a $\mathrm{HE}$ water heater and fan coil that meet both the space-heating and domestic hot water needs of the building.

ENR's technical assistance includes providing developers with model specifications that cover the four techniques of the SI package, orienting and training the developers and contractors during the course of the specification development and bidding process, and quality control inspections during construction.

ENR provides financial assistance in the form of grants of $\$ 2,000$ per unit to cover the incremental costs of SI upgrades in multifamily building rehabilitation. By comparison, rehab costs in these buildings range from $\$ 50,000$ to $\$ 80,000$ per unit.

As of March 1994, seven multifamily buildings (109 units) in Chicago had been rehabbed with SI building techniques. Detailed information about what SI features were applied in the first seven buildings is available from ENR (Knight 1994). As shown in Table 1, the seven SI buildings have apartment space heating indices ranging from 3.55 to 11.2 British thermal units per square foot per heating degree-day (Btu/ $\mathrm{ft}^{2} /$ degree-day). Five of the buildings have indices in the range of 3.55 to $5.33 \mathrm{Btu} / \mathrm{ft}^{2} /$ degree-day. Several likely causes exist for the high values over 11 at the remaining two buildings. These two are the only buildings with central heating systems, which are considerably less efficient than the individual heating systems in the other five buildings. Furthermore, the central heating systems also provide heat to the common areas of these buildings, including the basements and interior stairways. The indices for the other individually heated buildings do not include any consumption for the common area heating.

Another 131 units are currently being rehabbed; by the end of 1994, ENR expects to have 240 units completed. An additional 17 buildings (297 units) are scheduled for SI rehab in the next couple of years.

\subsection{ENERGY-EFFICIENT MODERATE REHAB}

Our preliminary surveys indicate that, in Chicago, moderate rehab projects are at least 10 times more common than gut rehab projects. ${ }^{1}$ "Moderate rehab" refers to a wide

1 This number is based on discussions with Chicago area practitioners such as William McCullom, of William McCullom and Associates, who specializes in the rehab of multifamily housing, and William Goldmann, of the Community Investment Corporation, who specializes in financing multifamily rehab in Chicago. 
TABLE 1 Performance of Rehabbed Multifamily Buildings

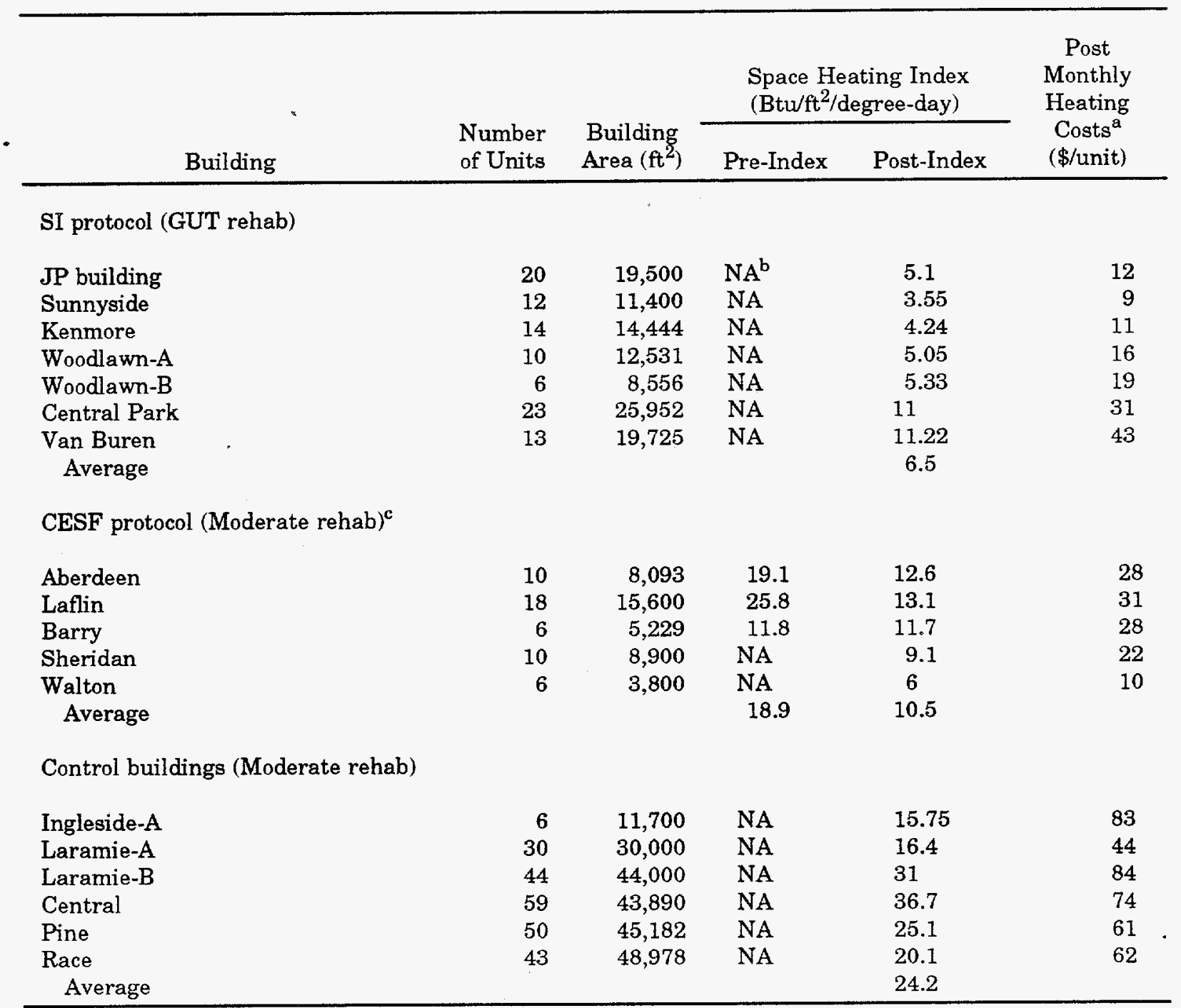

a Monthly heating costs are based on a gas price of $\$ 0.50$ per therm and 6,500 annual total heating degree-days.

b $\mathrm{NA}=$ not applicable.

c Aberdeen and the following four buildings were all participants in the heating Chicago Energy Savers Fund (CESF) sponsored by the local gas utility and the city of Chicago. All but Sheridan have the original walls. The exterior walls at Sheridan were gutted, insulated, and drywalled. All five of these buildings received individual heat. 
range of rehab interventions. The one common feature among all moderate rehab projects is that repairs are necessary; moreover, some demolition and framing and drywalling may be necessary, especially in kitchen and baths to accommodate new plumbing and electrical systems. Some efforts have been made over the last two years to adapt the SI techniques to moderate rehab projects; however, in each case the project evolved into a gut rehab.

The utility- and city-sponsored Chicago Energy Savers Fund (CESF) and its successor, the Peoples Conservation Loan Fund (PCLF), participated in about 20 moderate rehab projects from 1985 to 1990 . The current level of energy efficiency in rehab is difficult to gauge because of the diverse range of developers and funding sources. Developers that receive HUD funding have to meet certain energy efficiency standards set by the local municipalities that distribute the federal funds. However, to the best of our knowledge, Chicago developers who borrow from private lending institutions are not required to follow any energy efficiency guidelines when rehabbing multifamily housing.

\subsection{ENERGY EFFICIENCY RETROFIT PROGRAMS}

Even more common than moderate rehabs are retrofits of existing occupied buildings. A detailed review of energy efficiency retrofit programs for existing occupied buildings is outside the scope of this study; however, it bears mention because of the potentially large numbers of low-income renters that could benefit from well-spent energy efficiency investments. If we assume that at least $15 \%$ of Chicago's households qualify as poor and $60 \%$ of the poor families live in multifamily rental housing, then more than 100,000 low-income families live in multifamily housing.

From 1985 to 1990 , the CESF and its followup PCLF program provided energyefficient retrofits to more than 7,200 units of low- to moderate-income rental housing. The federal Weatherization Assistance Program (WAP) currently provides services to multifamily buildings in Chicago that have renters who meet certain income guidelines.

In 1989, the Chicago WAP demonstrated the first three comprehensive energy retrofits for these multifamily buildings. The projects were comprehensive in terms of treating the building envelope as well as the space heating and water heating systems. The envelope treatments included attic insulation, which has not been a standard part of the weatherization package for multifamily housing in Chicago. In 1990, about 200 multifamily units received comprehensive weatherization treatments. In 1990 , about $5 \%$ of the housing units serviced by the federal WAP throughout the country were multifamily rental units. This percentage is dramatically less than the $60 \%$ of all poor families who are renters. 


\section{ENERGY COSTS IN EXISTING LOW-INCOME HOUSING}

In 1994, a typical two-bedroom apartment managed by nonprofit, lower-income housing developers (such as Bethel New Life, the Kenwood Oakland Development Corporation, and PRIDE) in the low-income areas of Chicago has a rental charge of $\$ 450$ per month. The actual rents for two-bedroom apartments vary considerably among the lowincome neighborhoods in Chicago; however, to our knowledge no systematic evaluation exists of the rental costs for various family income levels. Similarly, some preliminary data are available on energy costs for this housing, although we know of no systematic evaluation of these costs. Table 2 represents our current best estimate of the average housing and energy costs for typical operating three-story walk-ups with their original central heating systems. The table includes all energy costs - those pertaining to building systems such as space heating, domestic water heating, and common area lighting and power as well as lighting and appliance usage by the residents.

At $\$ 60$ per month, space heating is the single largest energy cost component; it accounts for $40 \%$ of the total energy costs. The space heating cost shown in Table 2 is an average value based on utility bill data from 145 operating multifamily buildings that applied in the mid-1980s to a utility- and city-sponsored gas conservation loan program for low- and moderate-income multifamily housing (Biederman and Katrakis 1989). The cost of space heating corresponds to an average space heating index of $17.8 \mathrm{Btu} / \mathrm{ft}^{2} /$ degree-day - the value these buildings exhibited before receiving energy-saving retrofits. This program reflects a diverse range of building types, operating conditions, and management styles. The buildings range from single-room-occupancy (SRO) units in buildings of more than 80 units to threeand four-bedroom apartments in 6-unit buildings.

It is not clear how representative these buildings are of the total population of lowincome multifamily housing because of the self-selection that occurred as part of their decision to participate in an energy-saving program. However, the average space heating index does reflect a wide range of performance. The average space heating index in 31 of the 145 buildings before they received energy-saving retrofits was 18.0. This sample had a standard deviation of \pm 4.6 and included individual buildings with indices ranging from 8.3

to $28.3 \mathrm{Btu} / \mathrm{ft}^{2} /$ degree-day. After receiving energy-saving retrofits, this same group of buildings had space heating indices ranging from 8.5 to 22.5 , an average value of 12.9 , and a standard deviation of $\pm 4.2 \mathrm{Btu} / \mathrm{ft}^{2} /$ degree-day.

Apartment electricity usage from 175 low- and moderate-income apartments and gas usage from 51 of those apartments indicate apartment electricity and gas (cooking) bills that average $\$ 56$ per month. Again, these are average values from buildings whose owners and residents elected to participate in this program. Out of the rent, the building management pays about $\$ 100$ per month in gas and electricity costs for heat, hot water, and public area lighting. The energy costs account for about $30 \%$ of the total housing costs as defined by HUD. 
TABLE 2 Energy and Housing Costs in Operating Low-Income Housing ${ }^{2}$

\begin{tabular}{lcccc}
\hline \multicolumn{1}{c}{ Energy End Use } & $\begin{array}{c}\text { Number of } \\
\text { Dwelling Units }\end{array}$ & $\begin{array}{c}\text { Residents } \\
\text { per Unit }\end{array}$ & $\begin{array}{c}\text { Monthly Cost } \\
\text { (\$/unit) }\end{array}$ & $\begin{array}{c}\text { Percent } \\
\text { of Total } \\
\text { Energy Cost }\end{array}$ \\
\hline $\begin{array}{l}\text { Space heating } \\
\text { Domestic water heating }\end{array}$ & 2,320 & NA $^{\mathrm{c}}$ & 60 & 40 \\
Building electricity & 51 & 3.7 & 28 & 19 \\
Apartment electricity & 175 & 3.7 & 7 & 5 \\
Apartment gas & 51 & 3.7 & 24 & 16 \\
$\quad$ Total energy costs & & & 151 & 100 \\
Total resident energy bills & & 56 & \\
Average rent & & & 450 & \\
Total housing costs & & 506 & \\
$\begin{array}{l}\text { Percent energy costs of } \\
\text { total housing costs }\end{array}$ & & & & \\
\hline
\end{tabular}

a All samples are occupied dwellings that have been serviced by the Weatherization Assistance Program in Chicago.

b This sample has an average space heating index of $17.2 \mathrm{Btu} / \mathrm{ft}^{2} /$ degree-day and an average gross floor area of $1,286 \mathrm{ft}^{2}$ per dwelling unit. This is close to the average space heating index of $17.8 \mathrm{Btu} / \mathrm{ft}^{2} /$ degree-day for the approximately 2,320 low- and moderateincome dwelling units in 145 buildings serviced by the Chicago Energy Savers Fund from 1984 to 1986.

c $\mathrm{NA}=$ not applicable.

$\mathrm{d}$ This is an average of the costs from the 51 units in the Illinois Department of Commerce and Community Affairs study and another 124 units in the ENR lighting study.

Table 1 presents performance data from three groups of buildings that have been rehabbed. The "SI protocol" group includes buildings that have undergone substantial or "gut" rehab and incorporated the SI protocol developed by ENR. The average space heating index for the apartments in this group of seven buildings is 6.5, with a range of 3.55 to 11.22 (Knight 1994). The five buildings with indices below 5.4 all received new individual heating systems with efficiencies of 80 to $90 \%$. The average of their apartment space heating indices is $4.65 \mathrm{Btu} / \mathrm{ft}^{2} /$ degree-day. The two buildings with space heating indices of 11 or more have rehabbed central heating systems with seasonal efficiencies ranging from 50 to $70 \%$. 
The "CESF protocol" group includes four buildings that underwent moderate rehab; that is, the existing walls were kept intact. Another building, Sheridan, underwent a substantial rehab and received wall insulation. In each building, the original heating system was converted to individual forced-air systems (Katrakis and Wharton 1992). Most received attic insulation, some storm windows, and setback thermostats. After the rehab work, the average space heating index for these five buildings was $10.5 \mathrm{Btw} / \mathrm{ft}^{2} /$ degree-day, with a range of 6 to 13.1 .

The third group includes other buildings that underwent typical moderate rehabs during the late 1980s. Energy efficiency was not an explicit or formal consideration in planning or financing these rehabs. The existing plaster walls were kept intact, and no wall insulation was added. In some cases, the heating systems were changed. In other cases, the existing central systems were rehabbed. The average space heating index for these six buildings is $24.2 \mathrm{Btu} / \mathrm{ft}^{2} /$ degree-day. This average is dramatically higher than the average indices of the SI protocol and CESF protocol buildings; it is even significantly higher than the average pre-retrofit space heating index of the buildings described in Table 2. The buildings with the two highest space heating indices ( 31 and $36.7 \mathrm{Btu} / \mathrm{ft}^{2} /$ degree-day) have problems with the rehabbed central heating systems, which are being addressed by the current management.

The results indicate that the SI practice can substantially reduce the use of gas for space heating. If one eliminates the two control buildings with the highest space heating indices as outliers, the average for the control buildings is $19.3 \mathrm{Btu} / \mathrm{ft}^{2} /$ degree-day. Comparing the average space heating index for the SI building to the adjusted control group, the reduction in energy use for space heating is $12.8 \mathrm{Btu} / \mathrm{ft}^{2} /$ degree-day. If one compares the average space heating index of the SI buildings only to the control buildings with 30 or fewer units, the reduction in energy use for space heating remains approximately $10 \mathrm{Btu} / \mathrm{ft}^{2} /$ degree-day. 


\section{COMPARING HE AND TYPICAL REHAB COMPONENTS}

This section compares the typical rehab practices with HE practices embodied in ENR's SI method. Table 3 lists the components of the SI method.

\subsection{INSULATION}

The building elements that usually make up the thermal envelope include the exterior wall, the ceiling/floor cavity (building rim), the top-floor ceiling, and the basement ceiling. In addition, windows are an integral part of the thermal envelope.

Opportunities to increase the $R$-value (insulation value) of thermal envelope components exist when a building is receiving a substantial rehab. Thermal boundary building sections are usually opened during substantial rehab for replacement of plumbing, electrical systems, and heating systems. As building sections are opened, insulation can usually be added.

\subsubsection{Exterior Wall Insulation}

\subsubsection{Typical Construction}

A typical exterior wall in a building undergoing rehab in Chicago consists of bricks ( 2 to 4 wythes thick) and an air space created by furring strips, wood lath, and plaster. The total $R$-value of this wall is about 3.60, based on the American Society of Heating, Refrigerating, and Air Conditioning Engineers (ASHRAE) factors used for equipment sizing. In gut rehabs, the existing lath and plaster walls are demolished and disposed of. At present, two likely insulation treatments fall in the category of typical gut rehab: (1) insulate between existing furring strips and (2) install $2 \times 4$ framing and insulate.

Insulating between existing furring strips is by far the most likely treatment. After the plaster and lath are removed, the most common option currently appears to be placing 1-in. glass fiber batts between the furring strips and then mounting drywall on the strips. Sometimes, styrofoam panels are used instead of the glass fiber batts. In the past, gut rehabs have been done without adding any wall insulation.

Installing $2 \times 4$ framing and insulating is seldom done; the previous option is much more prevalent. In Chicago, rehabbers who currently apply for federal funding are told that all gut rehabs require framing-out the masonry walls with $2 \times 4 \mathrm{~s}$ and adding at least R-11 insulation. Apparently, this is motivating federally subsidized developers to resort to less costly moderate rehabs whenever possible. 
TABLE 3 Components of the SI Method

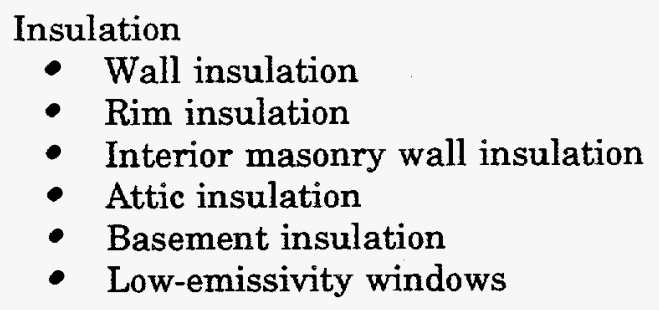

- Wall insulation

- Rim insulation

- Interior masonry wall insulation

- Attic insulation

- Basement insulation

- Low-emissivity windows

Air sealing

- Foil-backed drywall

- Caulk

- Foam

- Outlet covers

- Window sealing
Mechanical systems (options)

- Ventilation and exhaust:

- Bath and kitchen - intermittent or continuous

- Whole apartment outside air and exhaust

- Window trickle ventilators

- Heating plants (options):

- Forced-air furnaces with AFUE $>90 \%$ and central hot water systems

- Forced-air furnaces with AFUE $>90 \%$ and individual domestic water heaters

- Combined heating and domestic water heating systems with AFUE $>90 \%$ in each unit

- Central space heating and domestic water heating with fan coil units, convective baseboard, or radiant floors

In moderate rehab, the existing outside wall finish is retained. In Chicago, this is a more common practice (as much as 10 times more prevalent than gut rehab). Keeping the outside wall lath and plaster intact avoids the expense of demolition and disposal and the subsequent expense of the $2 \times 4$ framing. Furthermore, the demolition and disposal of lath and plaster have recently become more controversial because of the lead paint abatement issue.

In moderate rehab, the existing outside wall is repaired and, if necessary, is covered by a veneer of drywall. The new drywall can be installed directly onto the existing plaster wall surface. If the existing wall has excessive damage, it is sometimes necessary to install new fur strips or framing over the plaster and lath.

\subsubsection{SI Protocol}

The SI protocol requires a $2 \times 4$ framing system at 16 in. on center. Framing is installed an average of about $1 \mathrm{in}$. away from the wall to move the new wall away from all irregularities that are on the old wall. The 1-in. gap also provides a convenient passage for any new electrical conduit or other wiring. The top and bottom plates are attached to the subfloor and ceiling joists, respectively. Wood framing is typically recommended on the outside walls to reduce thermal bridging.

As shown in Figure 1, R-19 (6-in.) glass fiber insulation is used to completely fill the cavity. Although some compression of the batt and therefore loss of insulating value may occur, it is believed that this is more than compensated for by the complete filling of the cavity. The smaller 3.5-in. batts (R-11, 13, or 15) are not likely to fill the entire framing cavity and could result in convective currents and insulation by-passes that would degrade the performance of the insulation. Furthermore, the high-performance R-15 3.5-in. batts are still expensive. 


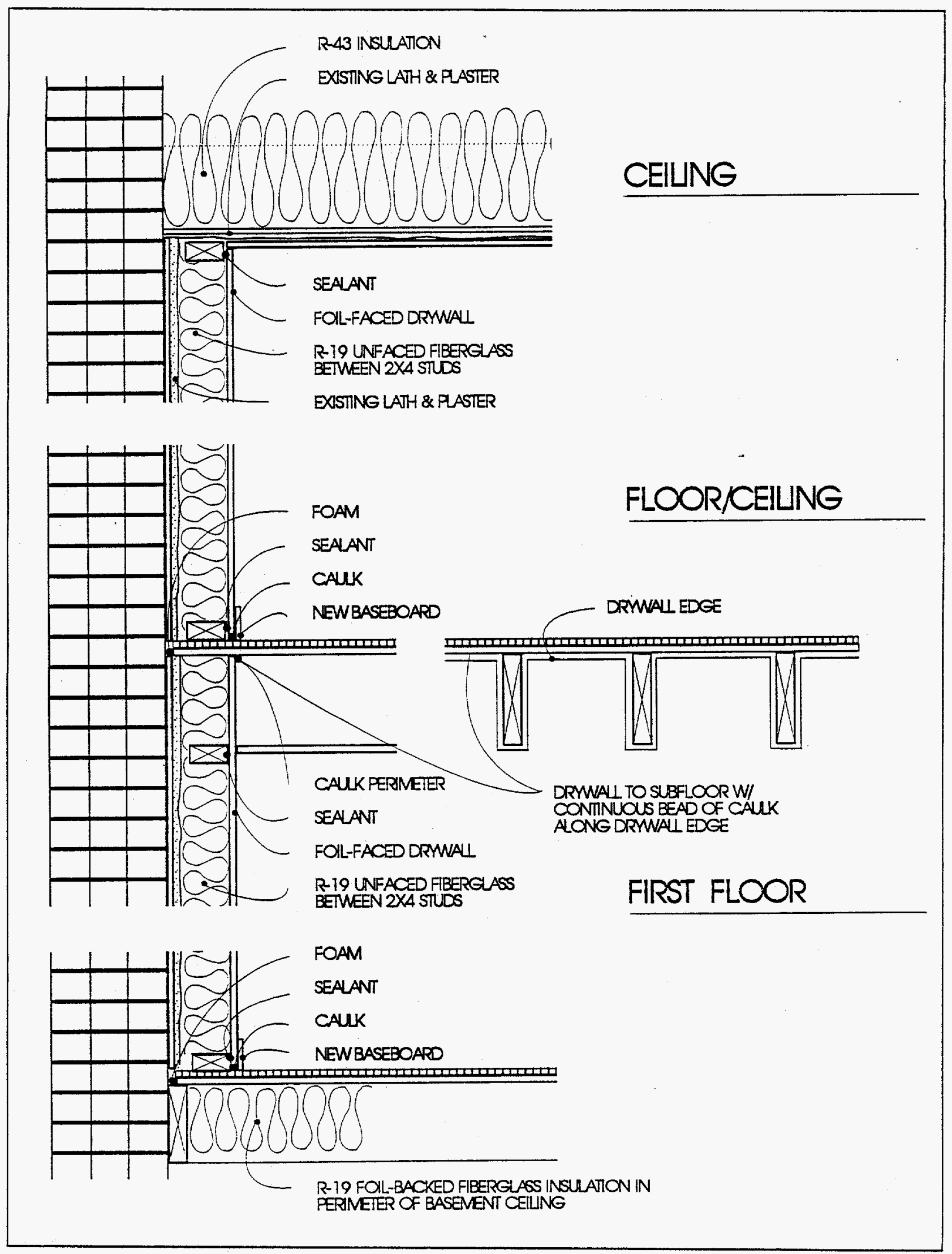

FIGURE 1 Typical Wall Section in SI Building 
Unfaced fiberglass insulation is installed. Kraft paper-faced batts are also no longer used because these batts are typically fastened to the interior face of studs (inset stapling) rather than the outer face. (Staples on the outer face of the studs tend to cause nail pops in the drywall.) Inset stapling creates a vertical cavity adjacent to the stud. Convection currents are established that reduce the effectiveness of insulation. Folds and creases in the kraft backing also contribute to lower $R$-values. In addition, the vapor retarder is not continuous over the face of the stud.

Polyethylene is not used as the vapor retarder. Section 5.3.2 explains how moisture control is addressed by the SI protocol.

\subsubsection{Other SI Options}

ENR and Argonne National Laboratory (ANL) are exploring other wall insulation strategies. The goal is to improve thermal performance, maximize the use of recycled and environmentally benign materials, and minimize first costs.

Blow-in insulation is generally considered to result in a higher $R$-value per inch than is possible with glass fiber batts because it is installed at a higher density and can flow around obstructions and irregularities to achieve a more complete fill. Also, blow-in techniques are compatible with a wide range of insulation materials, including more environmentally benign materials such as cellulose (recycled newsprint) and recycled glass materials. One commercially available dry-blow system consists of installing a nonelastic, plastic vapor retarder over the framing system. Cellulose insulation is blown in through slits made at the top of each framing bay. The plastic sheet does not bulge at cellulose densities of up to $3 \mathrm{lb} / \mathrm{ft}^{3}$ (Wardell 1993a). Another dry-blow approach is to install an intermediate layer of drywall to retain the blown-in insulation. The drywall may enable even higher densities ( 4 to $5 \mathrm{lb} / \mathrm{ft}^{3}$ ) and therefore better R-values. The second and final drywall layer results in a high-quality durable wall with extra thermal mass that can aid in temperature control and contribute to reducing energy costs. Dense-blown insulation can also be accomplished with a single layer of drywall. One possible approach is to install the drywall horizontally, leaving a 4- to 6-in. gap at the midpoint of the wall. The insulation hose would be passed through this gap and manually maneuvered to achieve the desired coverage and density.

Another commercially available blow-in product consists of an adhesive latex binder that is compatible with either cellulose or glass fibers. This product can be sprayed onto an exposed surface and troweled smooth (Wardell 1993b). The main issues to resolve with systems that use binders are the drying time and the environmental impact of the binders.

High- $\mathrm{R}$ rigid-board insulation systems have been considered and eliminated in gut rehab situations. It is considered too difficult and expensive to achieve a tightly filled cavity, especially in gut rehabs where the cavity includes the masonry surface. Also, until recently, high-performance rigid-board insulations were made from materials that emitted toxic compounds in fires. In some parts of the country, they are not used in interior applications 
(where they are separated from the living space only by drywall). Some possible applications exist for the new generation of environmentally benign high-performance rigid-board insulations.

\subsubsection{Rim Insulation}

\subsubsection{Typical Construction}

The "rim" is the exterior wall surface in the ceiling or floor cavity. If exterior wall insulation is planned, insulation may also be placed in the rim. Developers, believing that the ceiling and floor cavities are outside the heated area, do not always include rim insulation even though insulation is planned for the wall cavity. If built this way, heat simply bypasses the wall insulation through the rim.

Air leakage can also occur through the rim. The ceiling and floor cavities serve as a convenient path for air movement into the building interior walls via the ceiling.

\subsubsection{SI Protocol}

R-19 unfaced fiberglass insulation is installed in the rim as part of the SI package. The insulation is cut to fit snugly between the ceiling joists and is installed concurrent with the wall insulation as shown in Figure 1.

Although rim insulation does not effectively reduce air leakage by itself, rim insulation does help reduce conductive heat loss through the exterior wall. However, if the insulation is sealed to the framing system properly, an effective air barrier in the rim can be created. This process is discussed in greater detail in Section 5.2.

\subsubsection{Interior Masonry Bearing Wall}

\subsubsection{Typical Construction}

The objective of sidewall insulation is to provide a continuous thermal break between the interior and exterior (Figure 2). The key word is "continuous." Insulation can be placed behind corner studs of interior partition walls, thereby maintaining the continuity of the insulation and providing a thermal break between the interior and exterior. However, it is impossible to make this same break between an interior masonry wall and the exterior wall. These interior masonry walls provide bearing for floors and ceilings and are common in masonry multifamily buildings. These walls act as "fins" by wicking heat to the outside. This problem is not addressed in typical multifamily building rehab projects. 


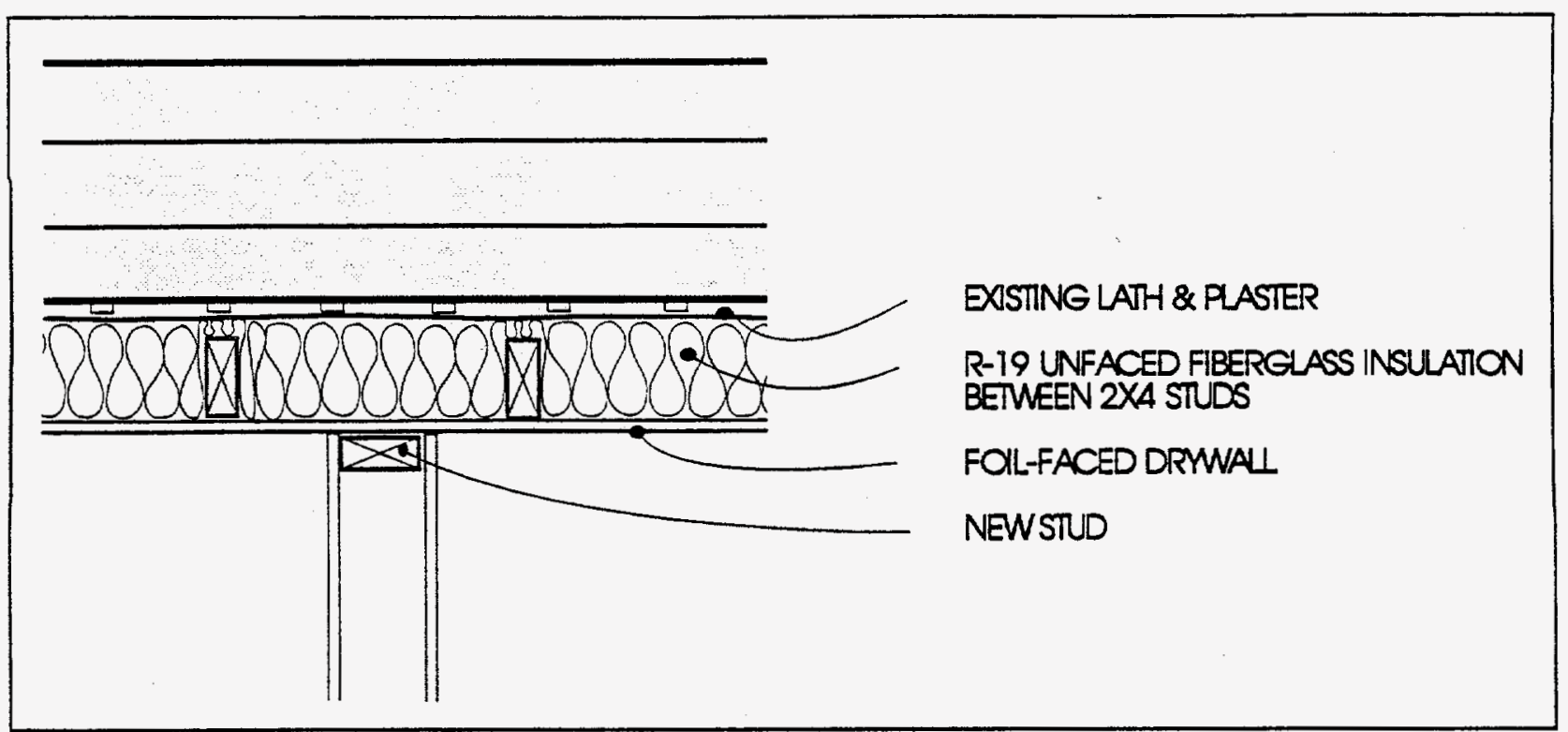

FIGURE 2 Typical Exterior Wall with Interior Partition (Interior partition framing is pulled away from the exterior wall to allow for installation of insulation. Continuous drywall behind the partition wall provides an air barrier.)

\subsubsection{SI Protocol}

"Fin" walls are unique to masonry structures. No references could be found that describe how to solve the heat bypass problem. Thus, the system shown in Figure 3 was developed for the SI program.

Typically, the plaster and lath on fin walls are also removed in a gut rehab. The furring strips often remain on the wall and serve as a nailer for new drywall. The first 4 to $6 \mathrm{ft}$ on the heated sides of the fin wall is insulated with 0.75 -in. polyisocyanurate insulation following removal of the plaster and lath. The 0.75 -in. insulation is used for two reasons. First, it fits neatly between the existing furring strips - the fin wall does not have to be framed as do the exterior walls. Second, it has a higher R-value per inch (7.2) than do other rigid insulation systems.

Although no research is documented as to the effectiveness of this system, it seems to be intuitively correct. The system is not $100 \%$ effective at preventing heat loss to the exterior; however, this heat loss is believed to be reduced, and a warmer interior surface temperature is provided at the corner. In addition; air sealing the fin wall is also done when the wall is insulated. 


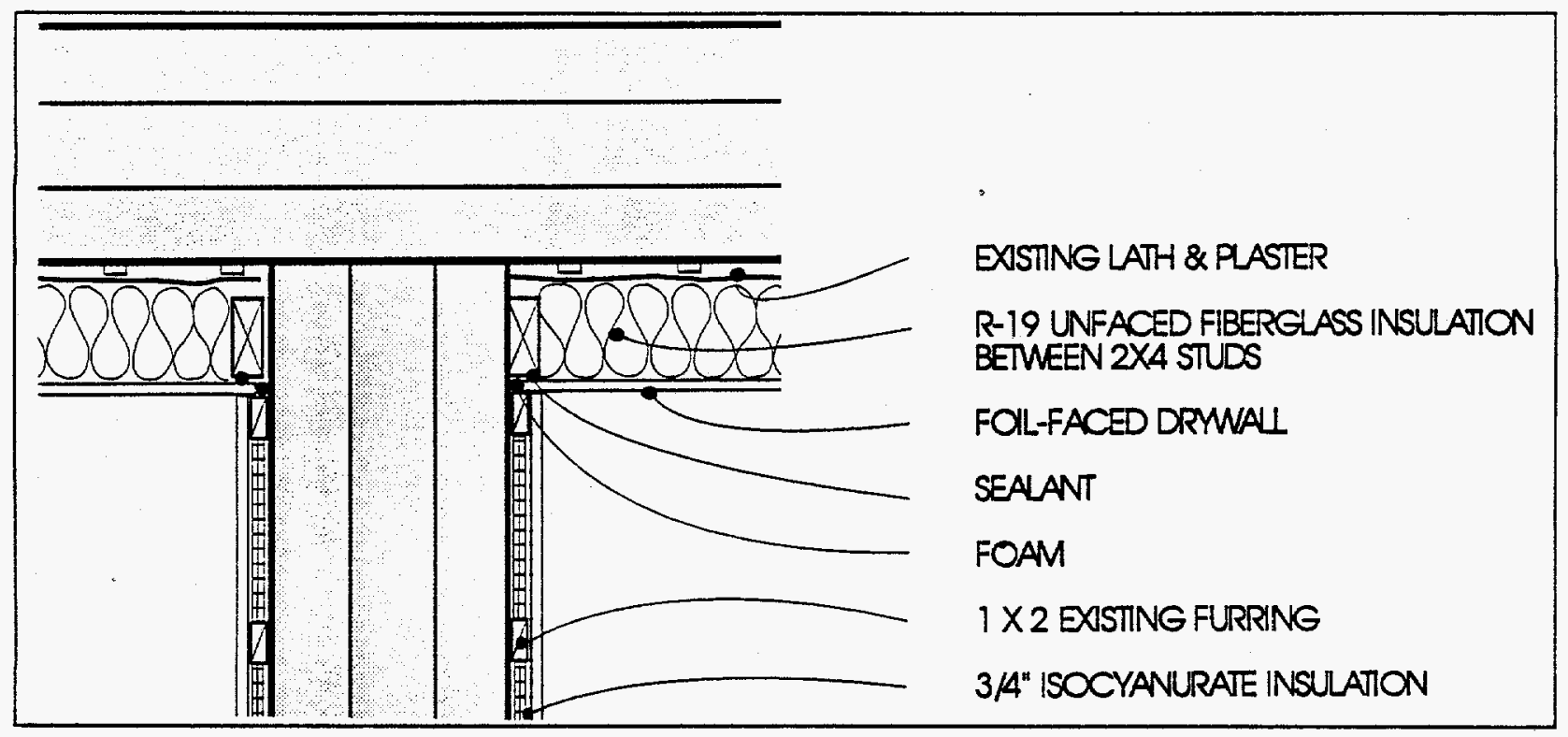

FIGURE 3 Typical Exterior Wall with Existing Bearing Wall (fin wall) (Fin wall is insulated with 0.75 -in. rigid insulation between existing furring strips. Sealing the first furring strip to the fin wall provides an air barrier.)

\subsubsection{Attics}

\subsubsection{Typical Construction}

Older masonry multifamily buildings are often said to have a "flat" roof, which is not entirely accurate. The roofs do pitch, usually front to back, creating a roof crawl space of about $4 \mathrm{ft}$ at the high end. The roof rafters are often located next to and slightly higher than the ceiling joists at the low end, leaving no crawl space at all. Typical multifamily building rehab includes either R-19 or R-30 ceiling insulation where adequate roof crawl space exists.

\subsubsection{SI Protocol}

Attic insulation levels are increased to R-43 under the SI protocol.

\subsubsection{Basements}

\subsubsection{Typical Construction}

Many multifamily buildings in Chicago are three stories with a basement. The basement floor-to-ceiling height is usually $8 \mathrm{ft}$, with about $4 \mathrm{ft}$ of the basement belowgrade. The basements are generally used for mechanical, laundry, and storage purposes. Portions of basement spaces are usually converted to apartments, often handicapped accessible, when the buildings are rehabbed. 
Exterior walls of basement apartments are finished in the same fashion as the abovegrade walls. Framing is placed over the interior wall finish for drywall installation. Insulation may be added to the wall just as for the abovegrade walls. Exterior walls in nonapartment basement spaces are usually not treated in rehab. Drywall is installed to the basement ceiling to provide a fire rating; however, the basement ceiling rim is usually not insulated.

\subsubsection{SI Protocol}

Basement apartments are insulated in the same fashion as the abovegrade walls. In the unconditioned portions of the basement, the rim of the basement is insulated with $\mathrm{R}-19$ insulation. The ceiling is then covered with drywall.

\subsubsection{Windows}

\subsubsection{Typical Construction}

Windows are in such disrepair in buildings undergoing substantial rehab that they must be replaced. Typically, double glazing is provided as window replacement. Double glazing may be achieved in one of two ways. First, a prime single-glazed window can be installed along with a single-glazed storm window. Second, a double-glazed prime window (without a storm) can be installed. Both methods are used in substantial rehab even though the second option has a distinct advantage.

Both layers of glazing must be in place to achieve double glazing. If a prime/storm combination is used, the tenant must put the storm window down during the winter. In other words, it is being left to the tenant to provide double glazing. If the tenant leaves the storm window up during the winter, single glazing is achieved even though the developer had "planned" for double glazing. Double glazing is achieved whenever the sash of a double glazed prime window is down; therefore, achieving double glazing is not left to the discretion of the tenant.

\subsubsection{SI Protocol}

Double-glazed windows with a low-E coating are required in the SI program. The low-emissivity (low-E) coating provides the same-R-value as a triple-glazed window at less cost and weight. 


\subsection{AIR SEALING}

\subsubsection{Typical Construction}

A conscious effort to include air sealing in a typical substantial rehab in Chicago is rare. Air sealing is limited to caulking exterior window and door frames to prevent moisture entry from the outside.

\subsubsection{SI Protocol}

Air leakage can be significant in multilevel buildings, and air sealing is addressed as part of the $\mathrm{HE}$ rehab. The objective of air sealing is to (1) reduce infiltration caused by outside air leaking into the building and (2) minimize air movement between units by the "stack" effect and minimize the "bypass" of warm air around existing insulation.

Air sealing can be accomplished at a relatively low cost by using inexpensive materials. Ironically, some of these same materials are often used in a typical rehab. Simply changing the manner in which they are installed, coupled with an understanding of air movement principles, can reduce air leakage. A modified version of ADA is used in the SI program for multifamily buildings. The treated components are described briefly in the following subsections.

\subsubsection{Masonry/Subfloor Joint}

When these buildings were originally constructed, furring strips were attached to the masonry wall after the floor joists were attached. The furring strips extend down between the floor joists. Therefore, when the subfloor was laid over the joists, it could not be installed up against the masonry because of the 0.75 -in. furring. This gap can be sealed with expanding foam. Wide joints may be first stuffed with scraps of fiberglass or drywall and then foamed. The current SI protocol specifies sealing this joint at each floor and assumes that if each floor is sealed it is not necessary to seal the roof crawl space (Figure 1).

\subsubsection{Fin Wall/Exterior Wall Joint}

Just as the fin wall presented a special insulation problem, it also presents an air-sealing problem. Caulk or foam is used to seal the furring strip adjacent to the exterior wall to prevent air movement into the fin wall (Figure 3).

\subsubsection{Foil-Backed Drywall}

This drywall, coupled with sealing key joints in the wall, is the primary air barrier between the conditioned space and the outside. The drywall is notched to fit around the 
ceiling joists where the joists are perpendicular to the masonry wall (Figure 1). The drywall is simply installed up to the subfloor where the ceiling joists are parallel to the wall.

This drywall system has one final advantage. Recall that foil-backed drywall is being used, with the foil serving as the vapor retarder. The vapor retarder is also continuous in the rim area. A polyvapor retarder is not installed in the rim area and, if used, kraft-faced batts do not provide a continuous vapor seal across the framing members.

In a typical rehab project, glue is often used to hold drywall in place until mechanical fasteners are installed to permanently hold it. Glue, and even caulk, will dry and crack over time, thus diminishing its effectiveness as an air barrier. Acoustical sealant, however, will remain pliable for a longer period of time. It is used to seal the drywall to the framing members. The joint between the drywall and the ceiling joists or subfloor is sealed with caulk or foam.

\subsubsection{Plumbing Stacks}

These chases, which can extend from the basement to the roof cavity, are sealed off to minimize the "stack" effect. If the opening is fairly small, foam or caulk is used. Larger openings require backing with ductboard or drywall followed by sealing with foam.

\subsubsection{New Penetrations}

Any new penetrations caused by the rehab are also sealed, usually by caulking. These penetrations include conduit through wall plates, panel boxes, and junction boxes.

\subsubsection{Electrical Outlet Covers}

A special cover plate is used in the SI program to minimize air infiltration through the cover plate and outlet. The plate has a gasket preinstalled on its back and spring-loaded covers. The spring-loaded covers also serve as a child safety item because the covers must be pushed out of the way to use the outlet.

\subsubsection{Window Sealing}

Pulley wells are packed with insulation. Spaces between the window and rough opening are stuffed with insulation and/or foamed as shown in Figures 4 and 5 . Wood mullions between windows are also insulated. 


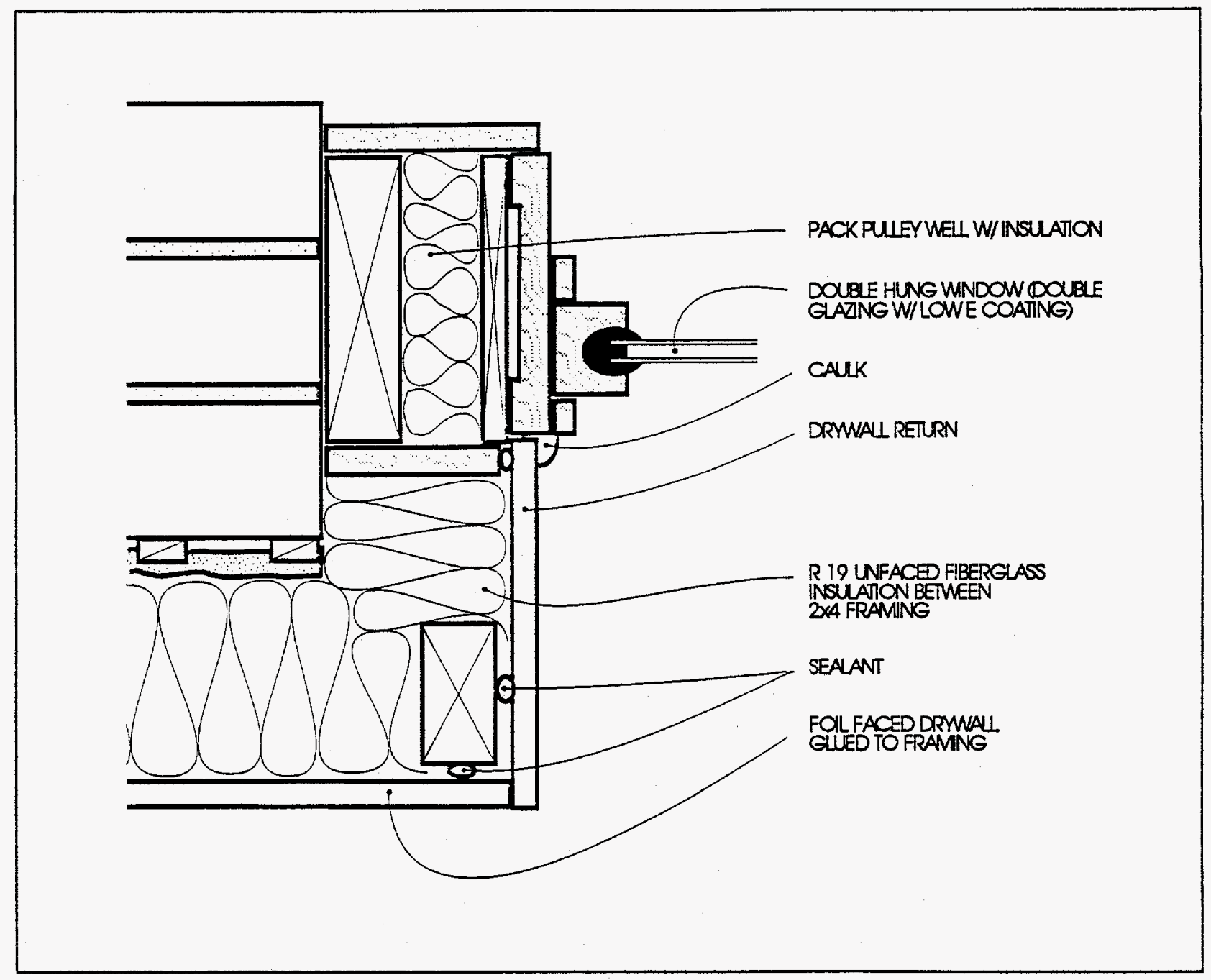

FIGURE 4 Existing Pulley Well Packed with Insulation (Drywall returns are insulated and sealed to the window frame.)

\subsubsection{Quality Control}

ENR conducts blower door tests to check the relative air tightness of each apartment. The desired tightness is defined to result in about $1 \mathrm{ft}^{3} / \mathrm{min}$ per square foot of floor area at a blower door induced pressure difference of 50 pascal. This tightness results in a natural air exchange rate of about 0.5 air changes per hour. The approach has been to avoid lower air exchange rates because of indoor air quality problems and the high cost of installing a continuous ventilation or an outside air supply ventilation system. (Current research is examining techniques for lower installed and operating cost opportunities for ventilation systems.) Conversely, it is desirable to avoid leakier apartments to avoid high heating costs. 


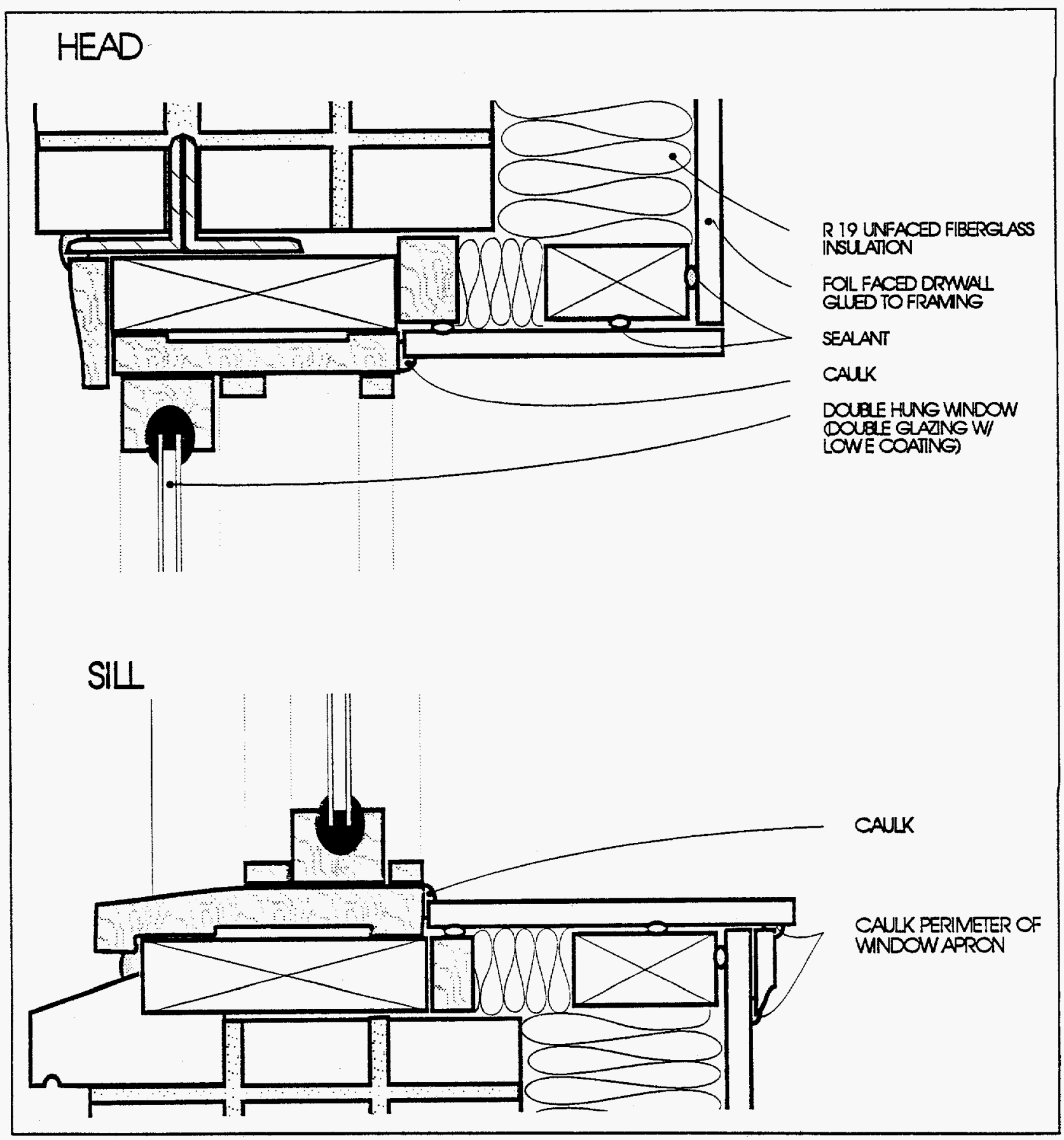

FIGURE 5 Window Head and Sill Insulated and Sealed to the Window Frame (Window stool and apron are sealed to the framing and drywall.) 


\subsection{MECHANICAL SYSTEM OPTIONS}

\subsubsection{Mechanical Heating Systems}

Buildings undergoing substantial rehab require a new heating system. The SI program looks at how the efficiency of a proposed heating system in a building rehab can be improved. Either a new central heating system is installed or forced-air furnaces are installed in each living unit, with the tenants paying the heating bills. In other examples, the individual furnaces are master-metered, and the owner pays the heating bills. Then, the owner apportions the gas bill each month to all the residents. A discussion of the relative merits of central versus individual heating in low-income housing will be reserved for another paper.

The SI program does not require one heating system over another. Although energy consumption can be significantly reduced with either system type in the SI rehab, measured consumption in buildings with new $\mathrm{HE}$ individual heating systems has been half of the energy used in buildings with renovated central steam heating systems. Therefore, the most common approach used to date has been individual heating systems with $90 \%+$ furnaces. The individual furnaces also provide thermostatically controlled heat for each apartment, thereby maximizing the residents' control over their indoor environment. In fairness to the central systems, they have not been designed to the same level of energy efficiency as the individual HE furnaces. Furthermore, it is much more difficult to find affordable central hot water or steam boilers that are as efficient and affordable as the residential furnaces. The corresponding water heating systems have been conventional commercial-grade heaters with storage tanks.

Another individual heat option that has been tried in several buildings is the combined space heating and domestic water heating appliances. These systems use a single $\mathrm{HE}$ water heating appliance to generate hot water that is used in a water-to-air heat exchanger to heat the air that is recirculated through the apartment. Both $80 \%$ - and $90 \%$ efficient water heaters have been installed.

ENR is exploring a more diverse range of heating systems in the most recent SI rehabs, which includes radiant flooring to minimize operation and maintenance costs. Another promising system is a high-performance central hot water system that may result in lower first costs, lower utility prices, and lower operation and maintenance costs.

\subsubsection{Mechanical Ventilation Systems}

In past SI projects, the ventilation scheme consisted of providing bathroom and kitchen exhaust fans that could be used by the residents to remove moisture. More recently, interest has focused on continuously operating systems or on systems that are automatically operated periodically. These more-extensive provisions for mechanical ventilation are 
envisioned in response to the improving tightness of the building envelope as the SI procedures are improved and contractors get more experienced.

One issue is how to minimize the number of openings through the building envelope. Each apartment requires its own source of fresh air. In moderately tight apartments, this can be achieved by using the exhaust fans in the kitchen and bath to drive the apartments to negative pressure and draw air through the myriad of small cracks in the envelope. Another option currently under investigation is the use of trickle ventilators, which let a small amount of outside air through special vents installed at each window. These ventilators work if the static pressure drop is sufficiently high across the thermal boundary. At present, it appears sufficient to have the exhaust fans and circulation fan run intermittently - only as necessary to maintain the desired air quality.

Finally, a standard practice in commercial applications is to penetrate the outside wall adjacent to each air handler to provide an outdoor air source to the air-handling unit. These systems can be outfitted with heat recovery systems to use the heat in the air being exhausted. At present, heat recovery is used occasionally in the northern parts of the Midwest; however, there doesn't seem to be a demand for it in Chicago. Its cost-effectiveness is highly dependent on the severity of the climate. 


\section{THE INGLESIDE BUILDINGS}

The Kenwood Oakland Development Corporation rehabbed a building more than five years ago that is shown as Ingleside-A in Table 2. The corporation more recently acquired two nine-unit buildings for rehab in the 4700 block of South Ingleside in Chicago. The buildings are across the street from each other and are identical in design and size. However, the $4737 \mathrm{~S}$. Ingleside building (Ingleside-B) had tenants living in the building up to the start of rehab. The 4746 building (Ingleside-C), on the other hand, had been abandoned for a number of years.

The 4737 building was being rehabbed as a 12-unit building with 3 units on the ground floor and 3 on each of the remaining 3 floors. The ground floor was divided into four quadrants, with three quadrants being apartments; the fourth quadrant was used for mechanical, laundry, and storage. On the top three floors, a unit extended the full length of the north side of the building and two units were designed for the south side of the building.

The 4746 building was rehabbed as a 15 -unit building. Three units were placed on the ground floor just as in the 4737 building, and four units were placed on each of the remaining three floors.

Originally, it was decided that the 4737 building did not require a substantial rehab; thus, the 4746 building was selected for SI rehab. But as work began on the 4737 building, it became apparent that it was in much worse condition than originally thought. A substantial rehab was performed for the 4737 building; however, SI building techniques were not used. The same contractors worked on both buildings.

\subsection{COMPARISON OF REHAB TECHNIQUES}

\subsubsection{Wall Insulation}

\subsubsection{4737 S. Ingleside}

In the 4737 building, the condition of the plaster and lath was better than that typically found in a building requiring substantial rehab. Most of the building was occupied up to the start of rehab. More importantly, the roof had no significant leaks; when walls are exposed to the elements, serious damage to the plaster and lath occurs, which require them to be removed or covered with a new framing system and drywall. In addition, the building had no fire damage.

The walls showed the stress of the years. Peeling paint was very common, and the walls were cracked and buckled in places. Wallpaper, installed in a number of rooms, had deteriorated. The walls were beyond simple patching and painting. 
Original plans called for installing 0.75-in. metal channels over the existing plaster and lath on all exterior walls and attaching drywall to the framing (Figure 6). This may be considered standard practice in a "typical" rehab. However, it was decided during the course of construction that much of the plaster and lath had to be removed before the metal framing could be installed, particularly in the bathrooms. In these cases, 0.75-in. metal channels were installed vertically to the masonry at about 24 -in. on center. The same size metal framing was then installed horizontally across the vertical members to provide a flush surface for installing the drywall where framing was installed over the plaster and lath. This framing system gave the wall a "checkerboard" pattern (Figure 7).

The amount of framing required was more than originally anticipated. In fact, it might have been easier (and perhaps cost effective) to forego the 0.75-in. framing in lieu of simply installing $2 \times 4$ framing over the existing plaster and lath. The plaster and lath could have remained. The cost of that demolition could have been applied to the additional cost of the framing.

Wall insulation was not called for in the original framing plans. This is also typical of "conventional" rehab. However, wall insulation was attempted in some parts of the building. R-11 fiberglass batt insulation was installed in the following.fashion. First, the paper backing was removed from the insulation. The insulation thickness was then split in half to about $1.5 \mathrm{in}$. Then, the insulation was cut to fit neatly within the checkerboard pattern of the double framing insulation system. Insulation was not continuous behind the framing members. This same technique was also used on some walls where only vertical framing was used.

The installation of insulation was sporadic despite its questionable effectiveness. The insulation was installed by laborers working for the general contractor and not an insulation contractor. It appeared that if the laborers were not busy, they would spend some time "insulating" the wall. Insulation was used in some walls and not in others. The drywall contractor installed drywall whether or not insulation had been placed in the wall. It is estimated that 25 to $30 \%$ of the exterior walls were insulated in this fashion. This practice is not typical in conventional rehab.

\subsubsection{4746 S. Ingleside}

The 4746 building had been abandoned for a number of years. The roof had numerous leaks, and all the windows were either missing or shattered. Consequently, all the plaster and lath had sustained major damage. The original scope of work called for removing all plaster and lath and was to use the same framing system as in 4737, that is, 0.75-in. metal channels. No wall insulation was planned.

The framing system was upgraded to $2 \times 4$ metal studs with unfaced R-19 insulation installation within the cavity. The cost to upgrade the framing was $\$ 0.75 / \mathrm{ft}^{2}$ of exterior wall. The R-19 insulation was installed at $\$ 0.45 / \mathrm{ft}^{2}$. 


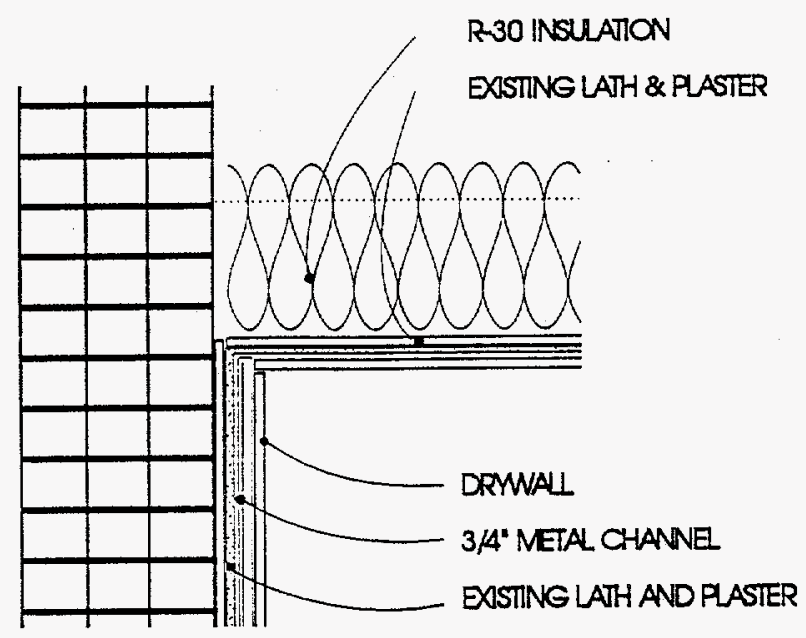

\section{CEILNG}

\section{FLOOR/CEILNG}

NEWBASEBOARD

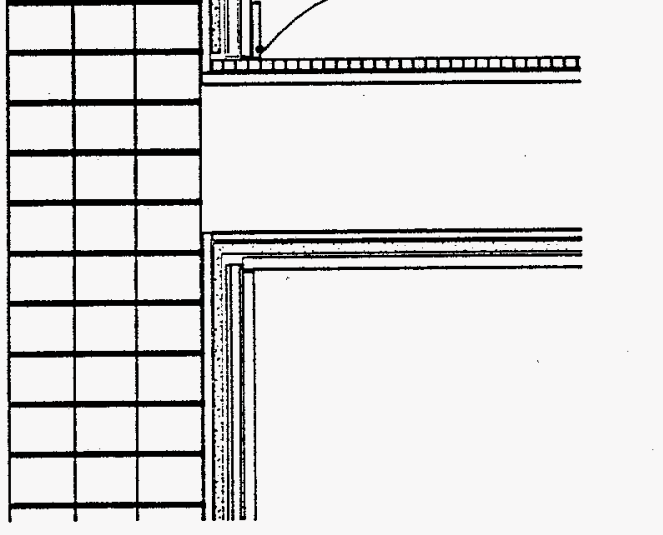

FIRST FLOOR

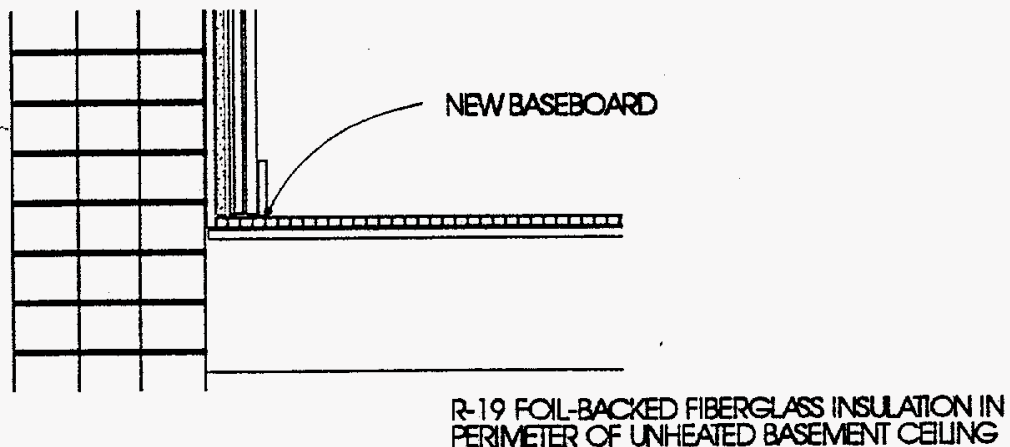

FIGURE 6 Wall Section Used in the 4737 S. Ingleside Building where Existing Plaster and Lath Remained 


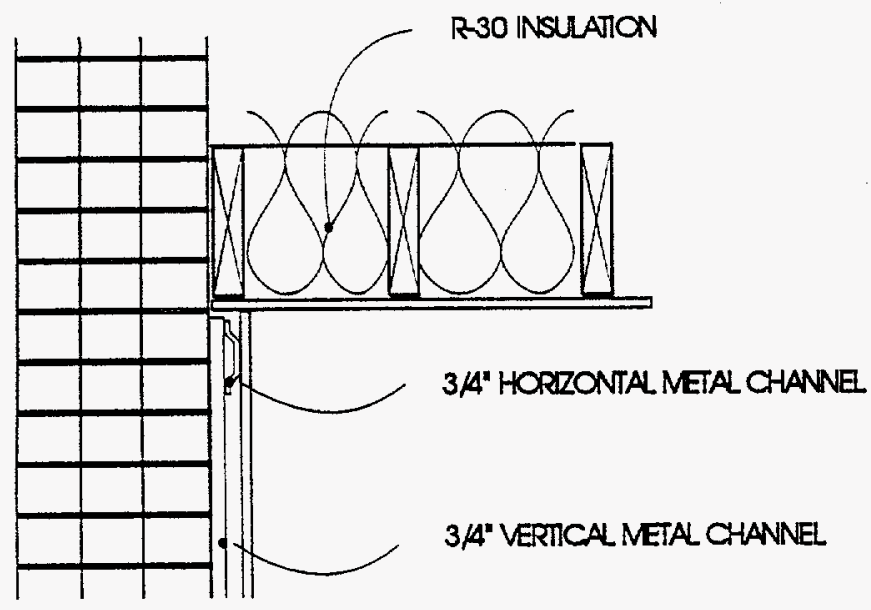

\section{CEIUNG}

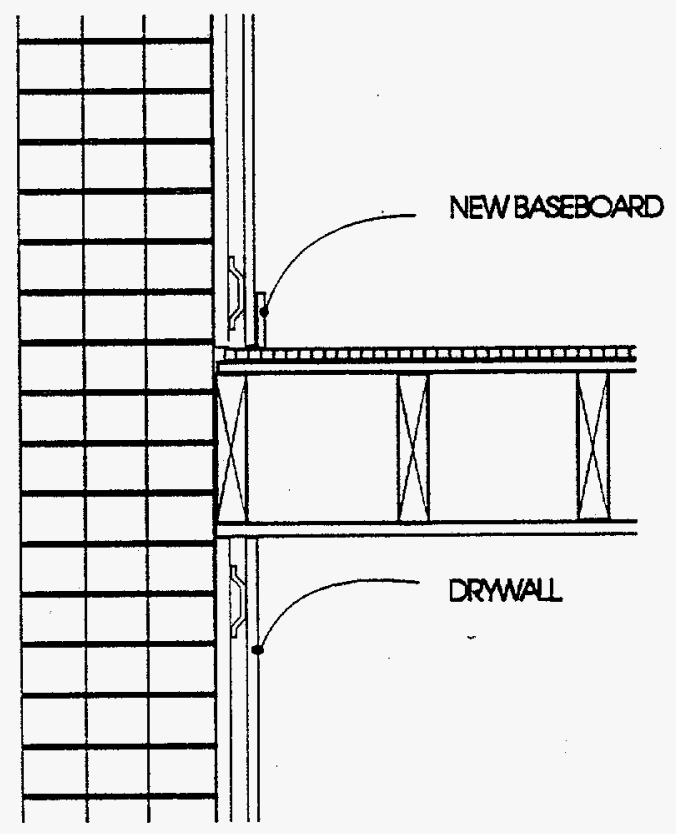

\section{FLOOR/CEIUNG}

\section{FIRST FLOOR}

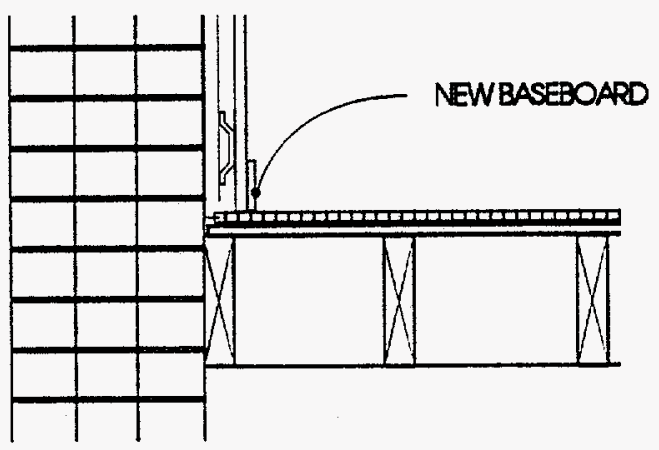

FIGURE 7 Wall Section Used in the 4737 S. Ingleside Building where Existing Plaster and Lath Were Removed 
The framing was installed on average about 1 in. away from the masonry wall to move the new wall away from all irregularities on the wall surface. The top and bottom plates were attached to the ceiling joists and subfloor, respectively. This is a typical framing practice where $2 \times 4$ framing is used in a masonry rehab project (Figure 8). R-19 (6-in.) insulation was chosen to completely fill the cavity. A standard 3.5-in. batt (R-11, 13, or 15) would leave a 1-in. air space between the insulation and exterior wall, which would allow for the establishment of convective currents. Although there is some compression of the batt (therefore not achieving the full R-19), it is believed the trade-off to completely sealing the cavity outweighs the slight loss of $R$-value.

Unfaced fiberglass insulation was installed. Polyethylene was not used as the vapor retarder. Rather, foil-backed drywall was included as part of the SI rehab. Foil-backed drywall has three advantages. First, because the vapor retarder is part of the drywall, it goes up in one step rather than two. Second, the integrity of the vapor retarder is maintained. Given the two-step process of poly and drywall, the poly could be damaged prior to drywall installation. Third, the foil-backed drywall is continuous across the face of the studs. This is an advantage over kraft-faced batts that are typically fastened to the interior face of studs (inset stapling) rather than the outer face, which also contributes to convective heat loss.

\subsubsection{Rim Insulation}

\subsubsection{4737 S. Ingleside}

Because wall insulation was not originally planned for in the 4737 building, rim insulation was also excluded. No rim insulation was placed in the building even though an attempt was made to insulate some of the walls.

\subsubsection{4746 S. Ingleside}

Rim insulation was also not planned for in the 4746 building; however, R-19 unfaced fiberglass insulation was installed to the rim as part of the energy package. The installed rim insulation cost was $\$ 0.45 / \mathrm{ft}^{2}$. The insulation was simply cut to fit snugly between the ceiling joists and was installed concurrent with the wall insulation (Figure 8).

\subsubsection{Interior Masonry Bearing Wall}

\subsubsection{4737 S. Ingleside}

One masonry interior bearing wall extends the length of the 4737 building from front to back. The plaster and lath were not removed from the fin walls. However, 0.75-in. metal channels were installed over the plaster and lath for new drywall installation. The fin walls were not air sealed or insulated before drywall installation (Figure 9). 


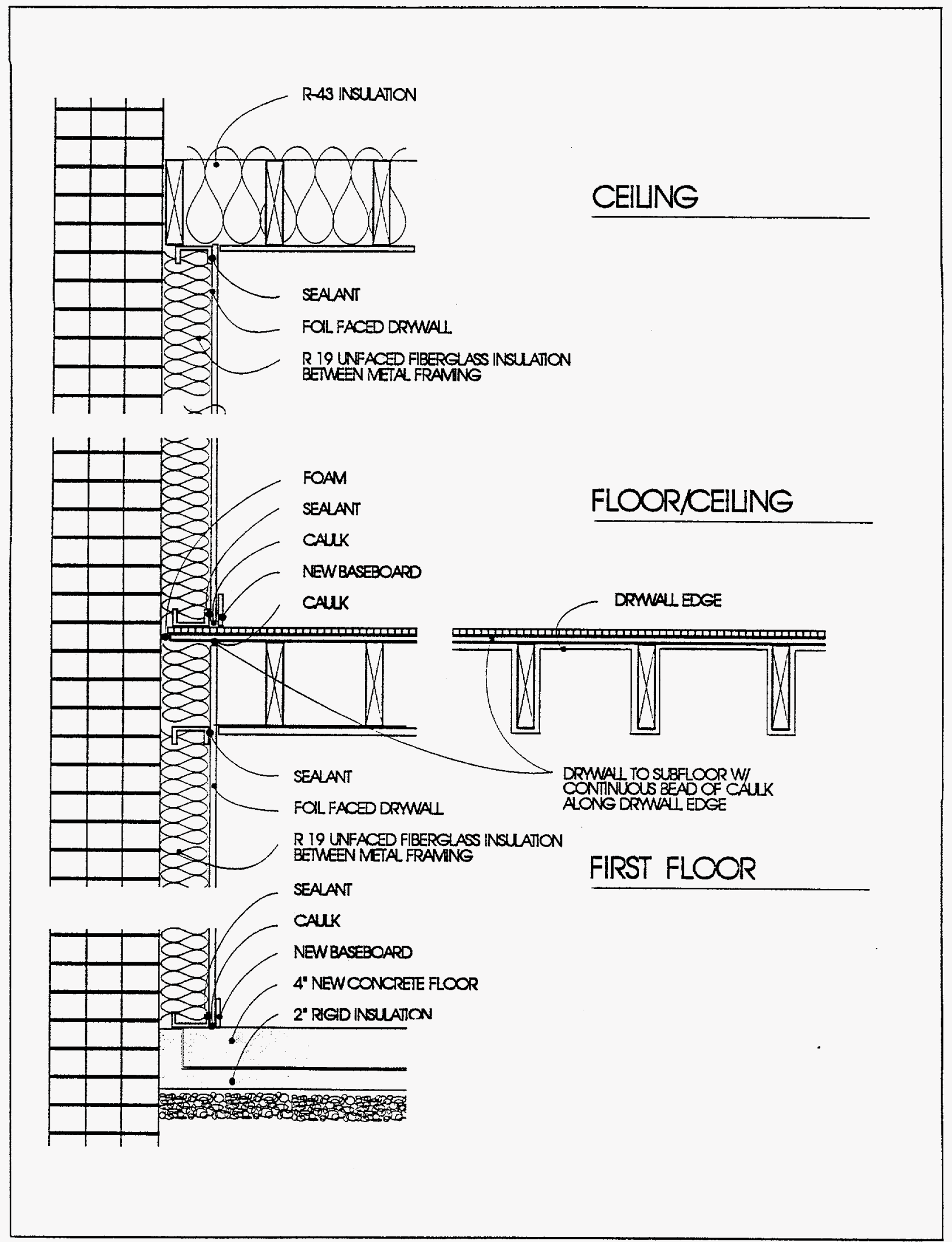

FIGURE 8 Wall Section Used in the $4746 \mathrm{~S}$. Ingleside Building 


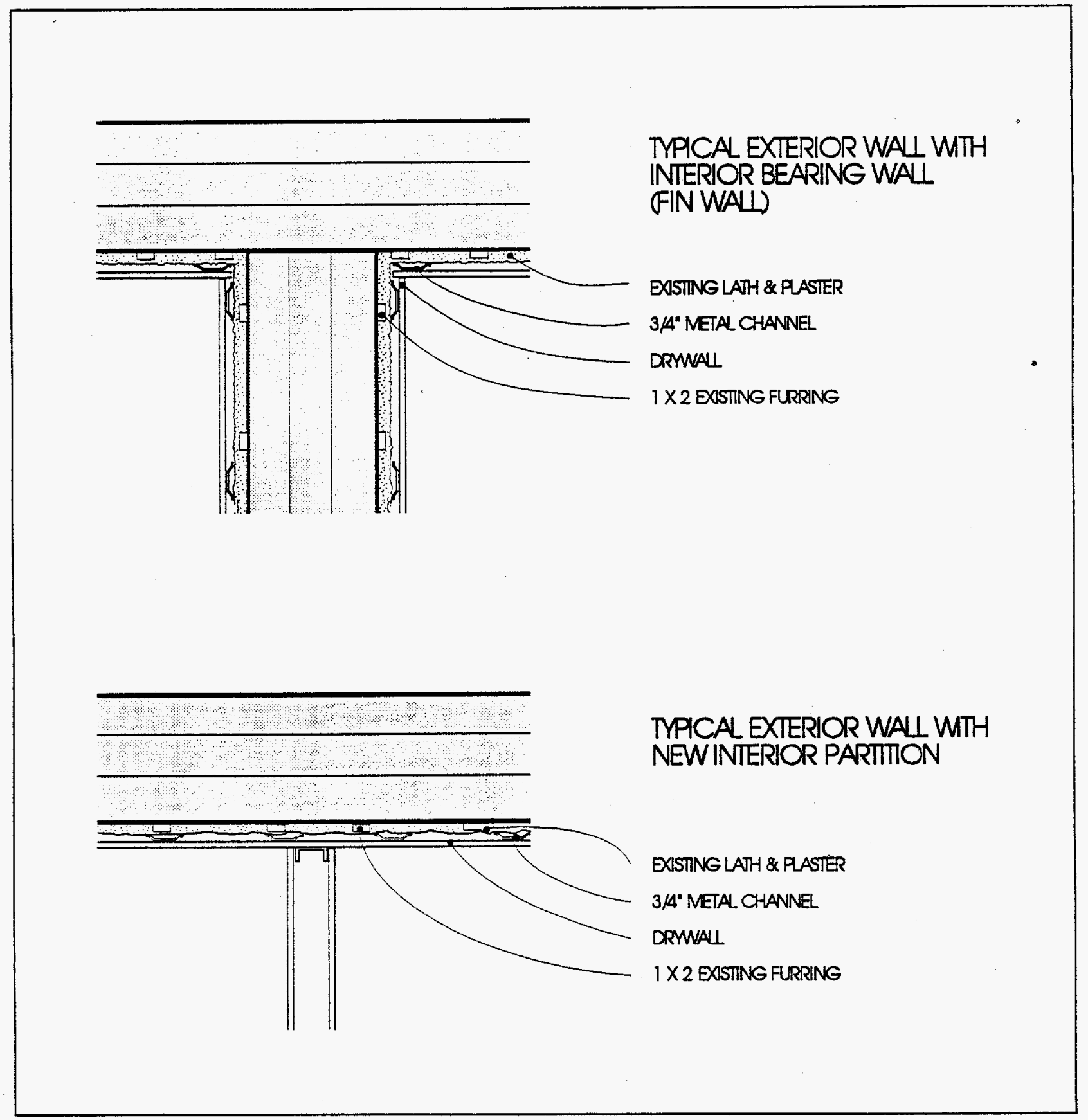

FIGURE 9 Plan View of "Fin" Wall and New Interior Partition Wall Used in the 4737 S. Ingleside Building 


\subsubsection{4746 S. Ingleside}

A masonry interior bearing wall identical to that in the 4737 building extends the length of the 4746 building from front to back (these buildings have identical designs). All plaster and lath, including furring strips, were removed from this wall.

The entire fin wall was framed with $2 \times 4$ metal framing in the same fashion as for the exterior walls; that is, the framing was pulled away from the masonry. Consequently, the wall was also insulated with $\mathrm{R}-19$ down to a point $6 \mathrm{ft}$ away from the exterior wall. The insulation cost $\$ 0.45 / \mathrm{ft}^{2}$ (Figure 10).

\subsubsection{Attic Insulation}

\subsubsection{4737 S. Ingleside}

R-30 cellulose ceiling insulation was installed in the 4737 building. The insulation was blown through access panels in the third-floor ceiling.

\subsubsection{4746 S. Ingleside}

R-30 cellulose ceiling insulation was originally planned in the 4746 building. The insulation was upgraded to $R-43$ cellulose at a cost of about $\$ 0.45 / \mathrm{ft}^{2}$ and installed in the same fashion as at the 4737 building (Figure 3). The attic insulation was installed by an insulation contractor.

\subsubsection{Insulation of Ground-Floor Slab}

The two Ingleside buildings are slightly different than the typical Chicago-style multifamily building in that they do not have traditional basements. Both Ingleside buildings have a ground floor, which served the purpose of a basement, located at grade level with three stories above it. Although these spaces were originally used for traditional basement functions, three apartment units were added on the ground floor in each building as part of the rehab. The remaining "basement" space was reserved for mechanical, laundry, and storage.

The ground floor in these buildings may be viewed as a slab on grade and should be insulated as such. Although difficult to insulate in a rehab, the opportunity to do so in these buildings was present. 


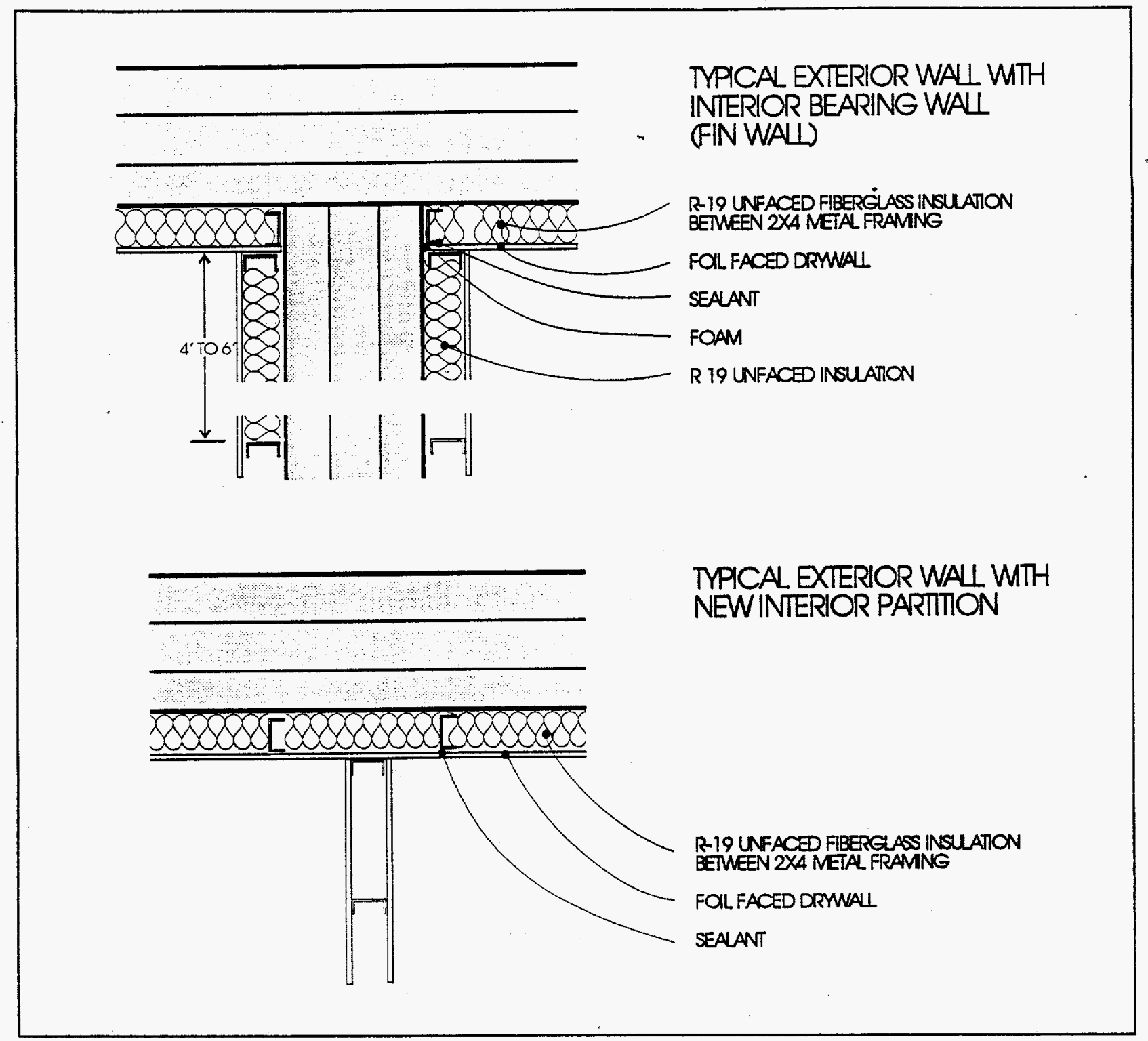

FIGURE 10 Plan View of "Fin" Wall and New Interior Partition Wall Used in the 4746 S. Ingleside Building 


\subsubsection{4737 S. Ingleside}

The existing basement floor of the 4737 building was in extremely poor condition. In addition, new drainage lines had to be installed beneath the floor to accommodate the three new units. Consequently, the existing basement floor was removed and a new concrete floor installed. No insulation was installed beneath the slab or at the slab perimeter.

\subsubsection{2 $4746 \mathrm{~S}$. Ingleside}

The basement floor of the 4746 building was in the same condition as that of the 4737 building. In addition, new drainage lines were required for the three new units. R-11 polystyrene insulation was installed beneath the slab and along the slab perimeter before the new concrete floor was poured (Figure 8). The slab insulation was installed at a cost of $\$ 1.15 / \mathrm{ft}^{2}$.

\subsubsection{Windows}

Windows were in such disrepair in the Ingleside buildings that they had to be replaced. Double-glazed prime windows were originally planned for both Ingleside buildings.

\subsubsection{4737 S. Ingleside}

Metal frame, double-glazed prime windows with a thermal break were installed in the 4737 building. No attempt was made to seal the space between the window and rough opening. In addition, existing pulley wells and wood mullions were not insulated.

\subsubsection{4746 S. Ingleside}

The same window used in the 4737 building was used in the 4746 building with the addition of a low-E coating. The addition of the low-E coating provides the same $R$-value that a triple-glazed window provides. The cost to upgrade to low-E was $\$ 2.00 / \mathrm{ft}^{2}$.

Air sealing the windows within the wall was also emphasized. Pulley wells were packed with insulation. Space between the windows and rough openings was stuffed with insulation or foamed. Wood mullions between windows were insulated.

\subsubsection{Air Sealing}

\subsubsection{4737 S. Ingleside}

A conscious effort to include air sealing in a typical substantial rehab in Chicago is rarely, if ever, made. Air sealing is usually limited to caulking the exterior frames of 
windows and doors. No attempt to provide a continuous air barrier in the building shell or to reduce air movement by the stack effect is made. The 4737 building is typical with respect to air sealing: it was limited to caulking the exterior window and door frames.

\subsubsection{4746 S. Ingleside}

An attempt to provide a continuous air barrier at the exterior shell was made to reduce air leakage into the 4746 building. All penetrations, cracks, and joints in unit perimeter walls, ceilings, and floors (not just the unit exterior) were sealed. Completed units are expected to achieve an air tightness level of $1,100 \mathrm{ft}^{3} / \mathrm{min}$ at an applied pressure difference of 50 pascal across the outside walls. This corresponds to about one-half an air change per hour under normal conditions. The measurements were made with a blower door.

In the 4746 building, the drywall was installed from subfloor to subfloor. The drywall was notched to fit around ceiling joists where the joists are perpendicular to the masonry wall. The drywall was simply installed up to the subfloor where the ceiling joists are parallel to the wall. The joint between the drywall and ceiling joists/subfloor was sealed with caulk or foam. Likewise, the bottom joint between drywall and subfloor was sealed with caulk. The drywall is now continuous from floor to floor as shown in Figure 8.

A common objection to the air-sealing work in buildings receiving SI rehab is that it will be too tight. This has not been (and is not expected to be) the case for the 4746 building. First, it is improbable that all holes, joints, and other "nooks and crannies" in these buildings will be sealed. Second, air tightness is checked with a blower door.

Air leakage sites identified with a blower door are recorded and become part of the contractor's punch list should the unit fail to meet the standard. However, no units tested in other buildings that received SI rehab have tested too tight; in fact, most are very close to the standard. This is expected to be true for the 4746 building.

Exhaust fans in the bathrooms and kitchens are required for buildings receiving SI rehab to ensure proper indoor air quality. The purpose of the exhaust fans, which must vent directly to the outdoors, is to remove moisture from the units. The bathroom exhaust fans in the 4746 building are rated at $75 \mathrm{ft}^{3} / \mathrm{min}$, and the kitchen exhaust fans are rated at $175 \mathrm{ft}^{3} / \mathrm{min}$.

Chicago building code does not require exhaust fans in bathrooms and kitchens with windows. All but one kitchen in the 4737 building required exhaust fans. Of the 15 bathrooms in that building, 8 required exhaust fans. In the 4746 building, all the kitchens and seven bathrooms required exhaust fans. The cost to install the additional eight exhaust fans was $\$ 500$ /unit. In addition, all the bathroom exhaust fans were upgraded to a combination light/fan that accepts a fluorescent lamp. The cost for this upgrade was $\$ 35 /$ fan. 


\subsubsection{Mechanical System}

\subsubsection{4737 S. Ingleside}

Before the SI protocol was introduced, a one-pipe steam system was originally proposed for both Ingleside buildings. The existing distribution system at the 4737 building was reused. A state-of-the-art, six-point, temperature-averaging thermostat was installed to control the boiler. The boiler is a conventional cast-iron sectional boiler with atmospheric burners. Main-line venting was replaced according to good practice in balancing steam supply for comfort. Radiator reventing remains to be done.

It is interesting to note that the contractor installed fairly $\mathrm{HE}$ domestic waterheating units in this building. These units are factory equipped with flue dampers.

\subsubsection{4746 S. Ingleside}

The 4746 building had been abandoned for some time, and the distribution system would have required major repair. Thus, as part of the SI program, the system was converted to a circulating hot water system. Any remaining radiators, steam, and condensate return lines were removed and replaced with a circulating hot water system with coppertubed, aluminum-fin baseboard in the apartments. The heat distribution system is divided into two or three hot water distribution loops from the front to the back of the building. Each loop covers three or four floors. The specifications also include an outdoor reset control with an outdoor temperature cutoff. It is not clear whether the contractor intends to insulate all the exposed distribution piping. Hot water is provided by a conventional cast-iron atmospheric boiler with an effective AFUE of about $70 \%$.

The cost to convert from a one-pipe steam-heating system to the hot-water-heating system was actually a credit of $\$ 2,800$. The reasons for the credit follow:

- The high cost of repairing the damaged and vandalized original steam system compensated for the cost of installing all the new baseboard and the associated piping and pumps for the hot water system; and

- A smaller and less-expensive boiler was possible as a result of the SI installed in the 4746 building and because of the inherently lower capacity of hot water boilers compared to steam boilers, which also need the extra capacity to propel the steam to its desired points of use. This made it possible to install a boiler rated at $550,000 \mathrm{Btu} / \mathrm{h}$ input rather than the new steam boiler rated at $900,000 \mathrm{Btw} / \mathrm{h}$ that was originally planned for each building. 


\subsection{PERFORMANCE COMPARISON}

Because of delays in the completion and occupancy of the Ingleside SI building, we do not have a complete heating season of energy use data for the occupied building. Airsealing work remains to be done. The boiler outdoor reset control was installed after the heating season, and the building was substantially overheated during the late winter and spring. Despite these factors, the preliminary results indicate that the SI building has a heating energy index of about $9 \mathrm{Btu} / \mathrm{ft}^{2} /$ degree-day. The conventional rehab is at about $12 \mathrm{Btu} / \mathrm{ft}^{2} /$ degree-day, which is better than expected. 


\section{THE COVENANT BUILDING}

We analyzed another recent SI building that is owned and managed by the Covenant Development Corporation. This building is especially interesting because of its mastermetered individual heating systems. The building management does bill the residents separately each month for all gas used at the building. Each resident's portion is determined by pro-rating according to the floor area of the apartment.

\subsection{METHOD OF ANALYSIS}

A run-time meter was installed at each apartment furnace in the Covenant building to monitor the gas that individual apartments used for space heating. Also, utility bills were analyzed from the one building utility meter that measures all gas uses: space heating in the apartments, space heating in the common areas (basements), domestic water heating, clothes drying, and cooking. Therefore, the on-time data from the furnaces in the apartments and the gas bills for the building made it possible to determine the total of all the other gas uses. at this building. The weekly gas usage values that are derived from the on-time data are regressed against outdoor temperature data to determine the linear regression coefficients and the balance point for each building or apartment.

The annual energy use is projected according to a normal weather year comprising mean daily weather data for O'Hare Airport. The data are derived by taking the average of the daily high and low temperatures for the last 30 years. The projection uses the coefficients from the linear regression with the daily outdoor temperature data. Two types of projections were tried. The All-Temperature method uses all the days in the heating season. The Modified-by-Balance-Point method only includes days with temperatures that, on average, are below the balance point derived from the regression analysis. Projected daily gas use for heating is assumed to be zero where the daily average outdoor temperatures are above the balance point for the apartment or building and also for the period from June 15 to September 1.

\subsection{ENERGY USAGE}

Table 4 shows the preliminary analysis of the performance of the six-unit Covenant building. The gas consumption derived from the on-time meter measurements varied considerably among the apartments. The highest user was Apartment $1 \mathrm{~N}$, which consumed 1,131 therms for space heating during the heating season. The lowest user was Apartment 2S, at 169 therms per heating season. This is a 6.7 to 1 ratio in energy usage. Note also that the three north apartments consistently consumed more energy than the south apartments. A number of factors contribute to variations between the north and south apartments. A small two-story building adjacent to the south allows solar gain to fully illuminate the south facade of the third-floor apartment and part of the second-floor 
TABLE 4 Regression Analysis for the Covenant Building ${ }^{a}$

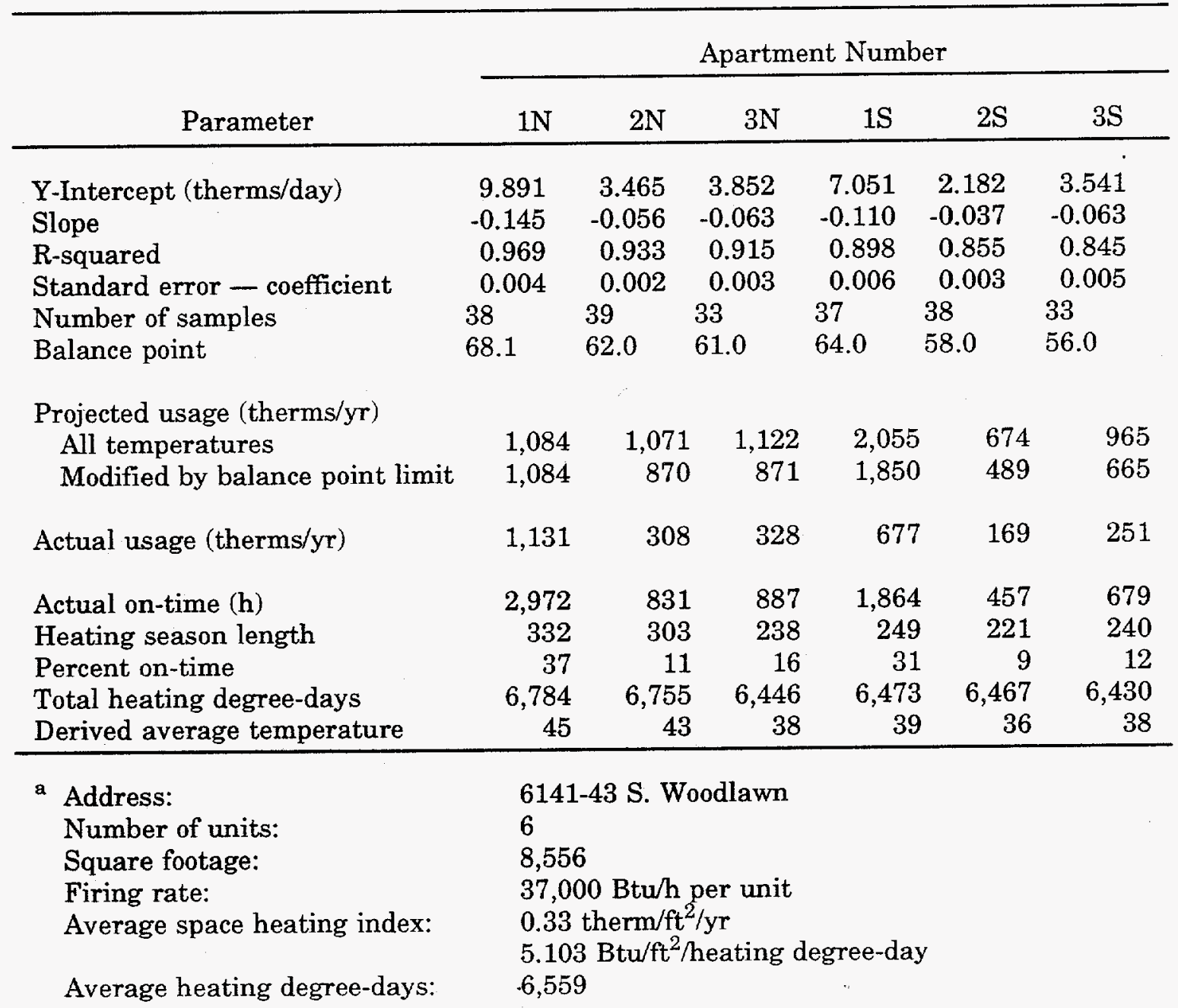

apartment. The adjacent building to the north is two stories; therefore, the third-floor apartment is exposed to the winter northwest winds. The flues of the two hot water heaters are on the south side and run through the south apartments. The basement furnace ducts are closed to the north side and open to the basement laundry on the south side.

The relative high consumption of both first-floor apartments can be explained by a combination of the following:

- The stack effect, which results in colder, unconditioned air infiltrating through first-floor windows and from the basement through the floor;

- Conduction losses through the floor to the basement, which is kept at $55^{\circ} \mathrm{F}$; and 
- The observed tendency of the first-floor residents to frequently change the thermostat setting to compensate for excessive or insufficient heat. This fluctuation may result in a lower than normal operating efficiency for the furnace.

A significant amount of gas is used to heat the basement area - more than $30 \%$ of the total gas used for space heating. This increases the energy index from 5.1 per degree-day to $7.25 \mathrm{Btu} / \mathrm{ft}^{2}$. This conversion permits a more direct comparison of the individually heated buildings and the centrally heated buildings, where a significant part of the heat loss of the boiler and distribution piping is used to heat the basement. The significant amount of gas used to heat the basement provides an incentive for increasing the amount of insulation and air sealing in the basement area.

The regression results shown in Table 4 are based on the burner on-time meter readings from each furnace. Note that the best correlation coefficient, $\mathrm{R}^{2}=0.969$, occurred at Apartment 1N, which had the most consumption. The other apartments used considerably less gas but also had significantly lower correlations. Except for Apartment $1 \mathrm{~N}$, the corresponding projected energy usage based on the linear regression parameters is consistently and considerably higher than the actual usage.

The next step in this analysis is to try using weather data from Midway Airport instead of O'Hare. Midway data may be more representative of the weather at the Covenant buildings. However, it may be necessary to take outdoor air measurements at the building because of its proximity to Lake Michigan and the influence of the "lake effect." Midway Airport is too far from the lake to be influenced by it.

\subsection{ENERGY COST}

The comprehensive gas master-metering at this building was done to minimize the utility costs to the residents. The residents do not have gas utility bills; however, the building management apportions gas use to the residents on the basis of floor area and gives each resident a monthly utility charge. Although Covenant passes all the gas utility costs on to the residents, the building management is able to get a better gas price than could any resident account. The price savings come from the utility because of the declining block rate structure. The buildings may also be able to take advantage of lower-priced, brokered gas service. Tables 5 and 6 compare energy use in an SI rehab and a conventional rehab.

Table 5 models the distribution of energy usage and costs for the various gas uses in the SI building. The total projected building gas usage $(6,896$ therms/yr) is essentially the same as the actual gas usage $(6,886$ therms/yr). The projected usage includes 1,200 therms/yr to maintain the reported $55^{\circ} \mathrm{F}$ temperature in the basement. This represents $40 \%$ of the total measured gas usage for heating all the apartments. 
TABLE 5 Modeled Distribution of Energy Costs in an SI Rehab ${ }^{a}$

\begin{tabular}{|c|c|c|c|c|c|c|c|c|}
\hline \multirow[b]{3}{*}{ Energy End Uses } & \multirow[b]{3}{*}{$\begin{array}{c}\text { Usage } \\
\text { (therms/yr) }\end{array}$} & \multicolumn{4}{|c|}{ Cost for Entire Building } & \multirow{2}{*}{\multicolumn{3}{|c|}{ Cost per Unit $(\$ / y r)$}} \\
\hline & & & & & & & & \\
\hline & & $\begin{array}{l}\text { Total } \\
(\$ / y r)\end{array}$ & $\begin{array}{l}\text { Percent } \\
\text { of Total }\end{array}$ & $\begin{array}{c}\text { Management } \\
(\$ / y r)\end{array}$ & Residents & Total & $\begin{array}{c}\text { Borne by } \\
\text { Management }\end{array}$ & $\begin{array}{l}\text { Borne by } \\
\text { Residents }\end{array}$ \\
\hline \multicolumn{9}{|l|}{ Gas usage } \\
\hline Space heating apartments & 2,849 & 1,823 & 39 & & 1,823 & 304 & & 304 \\
\hline Heating public areas & 1,200 & 768 & 16 & & 768 & 128 & & 128 \\
\hline Total heating. & 4,049 & 2,591 & & & & & & \\
\hline Domestic hot water & 2,190 & 1,402 & 30 & & 1,402 & 234 & & 234 \\
\hline Cooking gas & 657 & 420 & 9 & & 420 & 70 & & 70 \\
\hline Total gas & 6,896 & 4,413 & & 0 & 4,413 & 736 & 0 & 736 \\
\hline \multicolumn{9}{|l|}{ Electricity usage } \\
\hline Apartments & 2,307 & 231 & 5 & & 231 & 38 & & 38 \\
\hline Public areas & 800 & 80 & 2 & 80 & & 13 & 13 & \\
\hline Total & NA & 4,724 & 100 & 80 & 4,645 & 787 & 749 & 38 \\
\hline
\end{tabular}

a The modeled costs approximate the actual costs for the rehab of the 6-unit 6141-43 $\mathrm{S}$. Woodlawn building owned by the Covenant Community Development Corporation:

Super Insulation rehab

$\begin{array}{ccc}\text { Energy prices } & \text { Building } & \text { Resident } \\ \$ / \text { therm } & 0.64 & \mathrm{NA} \\ \$ / \mathrm{kWh} & 0.10 & 0.12\end{array}$

0.33 therms/ft $\mathrm{ft}^{2} / \mathrm{yr}$ space heating

0.09 therms/day/person for cooking gas

0.30 therms/day/person for domestic hot water

The actual total gas usage was 6,886 therms/yr $(\$ 4,306)$. 
TABLE 6 Modeled Distribution of Energy Costs in a Conventional Rehab ${ }^{\text {a }}$

\begin{tabular}{|c|c|c|c|c|c|c|c|c|}
\hline \multirow[b]{3}{*}{ Energy End Uses } & \multirow[b]{3}{*}{$\begin{array}{c}\text { Usage } \\
\text { (therms/yr) }\end{array}$} & \multicolumn{4}{|c|}{ Cost for Entire Building } & \multirow{2}{*}{\multicolumn{3}{|c|}{ Cost per Unit ( $\$ / y r)$}} \\
\hline & & & & & & & & \\
\hline & & $\begin{array}{r}\text { Total } \\
(\$ / y r)\end{array}$ & $\begin{array}{l}\text { Percent } \\
\text { of Total }\end{array}$ & $\begin{array}{c}\text { Borne by } \\
\text { Management } \\
(\$ / y r)\end{array}$ & $\begin{array}{l}\text { Borne by } \\
\text { Residents } \\
(\$ / y r)\end{array}$ & $\begin{array}{l}\text { Total } \\
\text { Cost }\end{array}$ & $\begin{array}{c}\text { Borne by } \\
\text { Management }\end{array}$ & $\begin{array}{l}\text { Borne by } \\
\text { Residents }\end{array}$ \\
\hline \multicolumn{9}{|l|}{ Gas usage } \\
\hline Space heating apartments & 6,845 & 4,723 & 57 & & 4,723 & 787 & & 787 \\
\hline Heating public areas & 1,200 & 792 & 10 & 792 & & 132 & 132 & \\
\hline Total heating & 8,045 & 5,515 & & & & & & \\
\hline Domestic hot water & 2,190 & 1,445 & 18 & 1,445 & & 241 & 241 & \\
\hline Cooking gas & 657 & 453 & 6 & & 453 & 76 & & 76 \\
\hline Total gas & 10,892 & 7,413 & & 2,237 & 5,176 & 1,236 & 373 & 863 \\
\hline \multicolumn{9}{|l|}{ Electricity usage } \\
\hline Apartments & 7,390 & 739 & 9 & & 739 & 123 & & 123 \\
\hline Public areas & 800 & 80 & 1 & 80 & & 13 & 13 & \\
\hline Total & NA & 8,233 & 100 & 2,317 & 5,915 & 1,372 & 386 & 986 \\
\hline
\end{tabular}

a These results are based on typical usage for conventional rehabs in a Chicago Energy Savers Fund study:

Conventional rehab

$\begin{array}{ccc}\text { Energy prices } & \text { Building } & \text { Resident } \\ \text { \$/therm } & 0.66 & 0.69 \\ \$ / \mathrm{kWh} & 0.10 & 0.12\end{array}$

0.80 therms $/ \mathrm{ft}^{2} / \mathrm{yr}$ space heating

0.09 therms/day/person for cooking gas

0.30 therms/day/person for domestic hot water 
Table 5 also includes projected electricity usage for the furnaces. The projected electricity usage assumes a fan run-time that is equal to the burner on-time. The actual fan run-time could be significantly longer because of the low settings of the fan cut-in and cut-out temperatures ( 85 and $115^{\circ} \mathrm{F}$, respectively). Table 5 assumes that the fan electricity is master-metered.

Table 6 includes data for a typical rehab with individually metered gas and electricity. The projected gas usage for domestic water heating and cooking gas is based on data from similar buildings and is assumed to be the same for the typical rehab and for the SI building.

The results indicate that the families in this building collectively enjoy about $\$ 1,270$ per year lower utility costs than they would in a typically rehabbed and metered building $(\$ 5,915$ from Table 6 minus $\$ 4,645$ from Table 5 ). The building management enjoys a savings of $\$ 2,237$ per year per apartment compared to a conventionally rehabbed and metered building ( $\$ 2,317$ from Table 6 minus $\$ 80$ from Table 5).

\subsection{CONSTRUCTION COSTS AND COST-EFFECTTVENESS}

Table 7 summarizes a total projected incremental cost of $\$ 2,121$ per apartment for constructing the SI features at this building. However, the actual incremental costs were $\$ 3,324$ per unit. These extra costs are primarily attributed to the relatively large threebedroom apartments in this building. The other Covenant building is a 10-unit building, and its projected and actual costs are not significantly different.

Table 8 summarizes the effect of the SI components on the cash flow of this building. By using the actual cost increment of $\$ 3,324$ and assuming a 30 -year mortgage at $8 \%$, the calculated expected debt service is $\$ 298$ per year. The building management obtains reduced utility costs of $\$ 373$ per unit for a net increase in cash flow of $\$ 75$ per unit per year. Each family saves about $\$ 212$ per year. Therefore, the total increase in cash flow is $\$ 287$ per year per apartment.

If we take into account the additional price reduction available from a gas broker (estimated at $\$ 0.10$ per therm in 1994) in master-metered buildings, the total increase in cash flow becomes more than $\$ 330$ per year per apartment.

\subsection{INFILTRATION MEASUREMENTS}

From April 21 to 25, 1993, before construction was completed at the 4746 Ingleside building, ventilation and infiltration measurements were made at the Covenant building and at 4734 Ingleside. Blower doors were used to measure the air leakage of individual and adjacent apartments. Also, tracer gases were used to measure the natural infiltration rates. These measurements are presented by Diamond et al. (1993) and may be extended to 4746 Ingleside at a later date. 
TABLE 7 Incremental First Cost per Apartment and Building (6141-43 S. Woodlawn) $^{\mathrm{a}}$

\begin{tabular}{|c|c|c|c|c|}
\hline Item & $\begin{array}{l}\text { Amount per } \\
\text { Apartment }\end{array}$ & Price & $\begin{array}{c}\text { Cost } \\
\text { (\$/unit) }\end{array}$ & $\begin{array}{c}\text { Total } \\
\text { Cost }(\$)\end{array}$ \\
\hline \multicolumn{5}{|l|}{ Insulation } \\
\hline Exterior wall & $904 \mathrm{ft}^{2}$ & $\$ 0.20 / \mathrm{ft}^{2}$ & 181 & 1,085 \\
\hline Exterior rim & $113 \mathrm{ft}^{2}$ & $\$ 0.64 / \mathrm{ft}^{2}$ & 72 & 434 \\
\hline Fin wall & $216 \mathrm{ft}^{2}$ & $\$ 0.84 / \mathrm{ft}^{2}$ & 181 & 1,089 \\
\hline Attic & $1,590 \mathrm{ft}^{2}$ & & 0 & 0 \\
\hline Low-E windows & $180 \mathrm{ft}^{2}$ & $\$ 2.00 / \mathrm{ft}^{2}$ & 360 & 2,160 \\
\hline \multicolumn{5}{|l|}{ Air sealing } \\
\hline Exterior drywall (perimeter) & 113 linear $\mathrm{ft}$ & $\$ 1.67 /$ linear $\mathrm{ft}$ & 189 & 1,132 \\
\hline Caulk & $1,596 \mathrm{ft}^{2}$ & $\$ 0.35 / \mathrm{ft}^{2}$ & 558 & 3,351 \\
\hline Foam & 1 unit & $\$ 20 /$ unit & 20 & 120 \\
\hline Outlet covers & 32 outlets & $\$ 1.85 /$ outlet & 59 & 355 \\
\hline $90 \%+$ Furnaces & 1 & $\$ 500$ & 500 & 3,000 \\
\hline Bathroom exhaust & 1 & $\$ 75$ & 75 & 450 \\
\hline Total & & & 2,121 & 12,725 \\
\hline
\end{tabular}

a Exterior building floor area: $\quad 9,573 \mathrm{ft}^{2}$ Apartment interior floor area: $1,426 \mathrm{ft}^{2}$ $15 \mathrm{ft}^{2}$ per window 12 windows per apartment

Building length: $\quad 60 \mathrm{ft}$ Building width: $\quad 53 \mathrm{ft}$ Floor height: $\quad 9 \mathrm{ft}$ 8 rooms per apartment 
TABLE 8 Cash Flow for SI, Master-

Metered Rehab: Covenant Community

Development Corporation

Six-Unit Building

\begin{tabular}{|c|c|}
\hline Cash Flow Items & Annual Cash Flow \\
\hline \multicolumn{2}{|l|}{ Management } \\
\hline \multicolumn{2}{|l|}{ First cost } \\
\hline Budget & $\$-2068 /$ unit \\
\hline Actual & $\$-3324$ /unit \\
\hline Debt service & $\$-298 / y r /$ unit $^{\mathrm{a}}$ \\
\hline Utility costs & $\$+373 /$ yr/unit \\
\hline Subtotal management & $\$+75 /$ yr/unit \\
\hline \multicolumn{2}{|l|}{ Residents } \\
\hline Utility costs & $\$ 212 /$ yr/unit \\
\hline Total improved cash flow & $\$ 287 /$ yr/unit \\
\hline
\end{tabular}

${ }^{a}$ A 30-year mortgage at $8 \%$ has a capital recovery factor of 0.0896 based on the actual budget. 


\section{CONCLUSIONS AND RECOMMENDATIONS}

\subsection{FACTORS THAT AFFECT THE EXTENT OF IMPLEMENTATION}

Five identified participants have critical roles in incorporating energy efficiency in low-income housing: developers and managers, residents, financiers, design consultants and project managers, and contractors. Local government administrators and their policies also play a significant role in facilitating or inhibiting energy efficiency improvements. An effective energy cost-cutting strategy has to take into account the perspectives and barriers associated with each group.

The following review of factors and perspectives is based on our working experience with about a half-dozen low-income housing developers, architects, and designers and preliminary discussions with project managers, government agencies, and community-based organizations that sponsor and implement energy programs for low-income housing. We hope this discussion will facilitate the organization of a process to create solutions and programs that specifically work with each group. These findings are preliminary and are based on a small sample of interviews and on anecdotes. However, they may be useful in organizing a more comprehensive and representative process.

\subsubsection{Developers and Building Managers}

Nonprofit housing groups appear to have the following perspectives and barriers:

- As with most business enterprises, the management style tends to focus on managing income rather than managing costs.

- Community development corporations generally lack the knowledge, incentive, and staff to plan and implement an energy cost-cutting component for their housing programs.

- Housing developers do not understand the cost-cutting potential of energy efficiency and conservation practices. The belief persists that "energy efficiency" inherently means "high-tech" solutions, and developers are wary of high-tech solutions and do not trust their feasibility or appropriateness. These beliefs and reservations translate into energy efficiency being a de facto low priority.

- Implementing energy efficiency features is seen as taking resources away from other, more important, investments. Concern exists that it may delay the rate of rehab completion, reduce the number of rehabbed apartments, or reduce the money available for other rehab features.

- Design for buildings in low-income areas must take into account the higher social costs from vandalism (McCullom 1993). This concern 
makes it important to avoid accessible products and materials that have a perceived high market value.

- Owners are faced with the split-incentive problem in multifamily housing (Levine et al. 1982). If the owner pays for heating costs, the residents do not have much monetary incentive to curb their heating requirements. On the other hand, if the building is individually metered for heating, the owner does not have a strong monetary incentive to create and maintain energy-efficient housing.

- Federal subsidies of utility costs are also a potential barrier because they serve to reduce the monetary incentive to implement energy efficiency measures. It is not clear how common these subsidies are or their future status; however, this issue needs clarification.

\subsubsection{Residents}

Of all parts of the population, lower-income residents are often least able to afford the time and expense to find and invest in energy-efficient appliances and lighting. They do not have the available capital and financing. Their communities are least likely to have the commercial outlets for energy-efficient products. Low-income residents typically do not have access to publicly available information on energy efficiency opportunities. In Chicago, most low-income residents live in master-metered buildings where changing their energy consumption habits may not affect their housing costs.

\subsubsection{Financiers}

Loan officers may or may not be familiar with the range of available energy-efficient options. We know one construction manager who had to work hard to convince a bank loan officer to accept the extra cost to insulate the building roof. Another construction manager was told by his bank to include attic insulation in his project. Typically, banks are not in a position to assess whether a building has incorporated state-of-the-art energy efficiency features. The energy-efficient features may not even be an issue if they are incorporated into the whole construction and financing plan. They appear to become an issue when the developer requests additional financing for specific energy cost-cutting features that require going beyond typical loan-to-value ratios. In general, the loan approval process lacks systematic review of the cost reduction opportunities. Loan officers are not in a position to include the increased security of loans that result from increased energy efficiency. It is not even an issue to banks unless they portfolio the loans. It may be more of an issue to the secondary market that buys these loans. 


\subsubsection{Design Consultants and Project Managers}

For design consultants and project managers, incorporating energy efficiency features requires more work: creating new design procedures, increasing analysis and verification, reviewing new products and field procedures, changing schedules, añd perhaps working with new consultants and contractors. All these features add cost, uncertainty, and risk, especially the first time they are used. All too often, these energy efficiency requirements are added so late in the life of a project that it requires revising plans, delaying schedules, and increasing costs (Lovins 1992). Sometimes, these requirements are added after the contractors provide estimates or bids.

\subsubsection{Contractors}

Contractors play a key role in implementing these improvements. They are particularly a crucial element in low-income housing developments that are operating on -especially tight margins. They may have less construction management and technical capacity than contractors who work on more lucrative contracts. Vendors of energy-efficient products mention that they do considerably more business with contractors who work in suburbs that are relatively more affluent than most inner-city areas. Even communication becomes an issue when the contractors or their subcontractors are not conversant with English (McCullom 1993).

\subsubsection{Local and Federal Government Policies}

As described earlier, the SI features open up opportunities for reducing the size and expense of forced-air distribution systems. It is now feasible to install simpler air distribution with much less sheet metal and less labor. Local building code officials have shown some apparent resistance to permitting this innovation. One likely reason is opposition from local unions to changes that could possibly reduce their business.

The local municipal administrator of HUD financing has instituted a policy that all multifamily gut rehab projects that get federal monies must frame out their walls with $2 \times 4 \mathrm{~s}$ and insulate. Although well intentioned, this policy is having a perverse effect on the level of energy efficiency improvements in gut rehab. Developers who were planning to gut rehab and install at least 1-in. batts of insulation between the fur strips decide to switch to a more limited moderate rehab to avoid the expense of installing $2 \times 4$ framing and more insulation. The moderate rehab approach generally means no wall insulation will be added.

The federal guidelines on minimum room sizes, as well as general common sense and good practice, limit the extent to which the walls can be framed in and insulated. Therefore, the current SI protocol may not be applicable in certain building types. 


\subsection{RECOMMENDATIONS}

\subsubsection{Program Development}

The following recommendations are program development activities to be done locally, in the multifamily housing industries around each DOE and HUD support office. DOE and HUD program staff could encourage and support these activities.

- Expand the survey of multifamily housing developers. Expand the survey of the energy effectiveness of typical multifamily housing rehab practices to cover a significant portion of both the for-profit and nonprofit multifamily housing developers. Assess the relative energy efficiency and costs of lower-income housing with moderate- and highincome housing.

- Evaluate the effect of energy efficiency on housing affordability and investment risk. Assess the correlation between the level of energy efficiency of a building and (1) actual housing costs for the residents; (2) net operating income for the building owner; (3) rate of resident turnover and complaints; and (4) likelihood of foreclosure, loan default, or code violations.

- Assess HE improvements for various rehab and building upgrade strategies. Survey the level of activity and energy-saving opportunities in the following three areas: gut rehab, moderate rehab, and upgrades of operating buildings. Programs for existing buildings that could benefit from HE improvements include the federal WAP as well as local utility-based and private building management activities. Solicit input from local practitioners and facilitate programs and procedures that address the particular needs and opportunities in these areas.

- Implement energy efficiency performance standards and criteria. Develop and disseminate information that shows property developers and managers the value of energy-efficient building rehab practice and enables them to discern whether their consultants and contractors are incorporating an appropriate level of energy efficiency into their buildings. This process could include workshops for property developers and managers, a building certification process that would verify energy performance, and changes in municipal and state energy codes.

- Implement effective design, construction, and operation and maintenance practices. Develop and disseminate design and construction practices, standards and specifications, and operation and maintenance practices for each recommended energy efficiency component. Offer workshops for property managers, architects, engineers, and contractors for such 
critical HE features as wall insulation, air sealing, and HE heating and ventilation systems.

- Facilitate access to qualified practitioners. Develop referral lists of architects, engineering consultants, contractors, and financiers who understand and are comfortable with HE building system design, construction, and operation and maintenance. This process may also involve a certification process for these specialists.

- Develop comprehensive energy and resource cost-reduction programs. Expand beyond reducing space heating energy costs to reducing the cost of all utilities borne by building owners and residents. This could include the costs associated with providing proper ventilation and air quality, lighting and refrigeration, and hot and cold water.

- Evaluate HE practice in the context of current health and safety standards. Compare the environmental quality of $\mathrm{HE}$ housing and conventionally rehabbed housing against the latest standards of acceptable environmental conditions. Evaluate levels of indoor air pollutants such as $\mathrm{CO}_{2}$ and $\mathrm{CO}$. Investigate the implications of proposed new standards and local codes for lead abatement and control and indoor air quality for HE rehab. Do the HE features facilitate compliance, or do they require additional investments to achieve compliance?

- Adjust policies and program guidelines to facilitate cost-effective $H E$ practices. Survey local practitioners to identify ways to eliminate perverse outcomes of otherwise well-intentioned policies to promote energy-efficient building rehab.

\subsubsection{Technical Research, Development, and Demonstration}

- Improve efficiency of common area heating. Document the energy costs necessary to keep the common areas at acceptable temperatures in individually heated and in centrally heated buildings. Investigate insulation, building tightening, and heating system strategies to reduce the cost of conditioning basements and hallways.

- Investigate alternative wall insulation systems. Investigate (1) options for both open and closed wall cavities such as dense-pack insulation and (2) exterior insulation and sheathing systems.

- Compare heating system alternatives. Investigate the performance of heating systems that are designed for high efficiency. Put more emphasis on $\mathrm{HE}$ multizone central systems with various distribution 
systems (e.g., baseboard convectors, air handlers, radiant floor). Compare their cost-effectiveness with individual forced-air furnaces and domestic water heaters and with individual combined-space and domestic water heating systems.

- Improve efficiency of resident electricity usage. Document resident electricity bills and the portion that is going towards supplying their heating, ventilation, and air conditioning and indoor air quality needs for each renovation option.

- Compare individually metered and master-metered energy usage in HE buildings. Determine the difference in energy use between mastermetered and individually metered heating systems in HE buildings. Document the savings in energy costs from declining block rate structures, fewer utility service charges associated with master-metered utilities, and the opportunity for bulk-purchasing of gas. Also document the feasibility of the building management billing residents for their energy usage.

- Improve database on costs. Most of the HE techniques are not standard practice in the building industry; therefore, the actual implementation costs are not known. Develop a system to accurately monitor the real costs of interventions such as air sealing, dense-blow insulation, and rim insulation.

- Value engineer the HE practice. Perform a cost-effectiveness analysis on the individual $\mathrm{HE}$ components to simplify and reduce installation cost without sacrificing performance. Develop the appropriate design, specification, and quality control practices for each building renovation strategy (substantial or gut rehab, moderate rehab, and retrofit).

- Use the systems approach in design. Explore the opportunities to take advantage of synergies between the treatments that reduce heat loss for the building envelope and energy-efficient mechanical system design to minimize capital and operating costs. Some examples include reducing boiler size and piping and ductwork systems, lowering heating medium temperatures, installing dual-purpose (space heat and domestic hot water) piping, and locating all ductwork and distribution piping inside the thermal envelope.

- Evaluate trade-off between air sealing and maintaining indoor air quality. Investing in the increased tightness of the building envelope requires investing in mechanical ventilation to maintain adequate air quality. Investigate the feasibility of a range of options in ventilation controls for maintaining indoor air quality, including the use of $\mathrm{CO}_{2}$ sensors. Determine the optimal balance between these additional 
investments and the resulting indoor environment, utility and operation and maintenance costs, and component lifetime.

- Develop and evaluate multifunction technologies. These technologies have the potential to reduce first costs and operation and maintenance costs. One example is the combined individual HE space heating and domestic water heating units. Other potential technologies are distribution piping for both space heating and domestic hot water and forced-air distribution for heat distribution, ventilation, moisture control, and heat recovery.

- Document indoor health impacts. Document the indoor environmental conditions of the various rehab and energy efficiency strategies, including:

- Lead and asbestos exposure,

- The need for supplementary heating from gas ranges or electric space heaters,

- Quality of indoor air (measured $\mathrm{CO}$ and $\mathrm{CO}_{2}$ levels),

- Indoor temperatures and humidity levels, and

- Resident perceptions of indoor comfort.

- Assess the public health and environment impacts. Assess the contribution of $\mathrm{HE}$ rehab on meeting federal goals for reducing $\mathrm{CO}_{2}$ and mandates of the Clean Air Act Amendments for the region.

- Investigate the use of resource-efficient and environmentally benign building materials in rehab. Consider using recycled plastics as an alternative insulation material. Identify materials and interior finishes that do not outgas respiratory irritants or toxic materials.

- Consider integrating energy features in rehab option analysis. Perform a life-cycle cost analysis of the various energy efficiency options and the corresponding rehab approaches to determine the true cost and benefit of each approach. Of particular importance is assessing the lifetime of the various energy efficiency options, their corresponding rehab strategies, and their operation and maintenance requirements.

These recommendations are summarized in Table 9. 


\section{TABLE 9 Summary of Recommendations}

Program Development

1. Expand the survey of multifamily housing developers

2. Evaluate the effect of energy efficiency on housing affordability and security

3. Assess HE improvements for various rehab and building upgrade strategies

4. Implement energy efficiency performance standards and criteria

5. Implement effective design, construction, and operation and maintenance practices

6. Facilitate access to qualified practitioners

7. Develop comprehensive energy and resource cost-reduction programs

8. Evaluate HE practice in the context of current health and safety standards

9. Adjust policies and program guidelines to facilitate cost-effective high efficiency

Technical Research, Development, and Demonstration

1. Improve efficiency of common area heating

2. Improve efficiency of resident electricity usage

3. Compare individually metered and master-metered energy usage in HE buildings

4. Investigate alternative wall insulation systems

5. Compare heating system alternatives

6. Improve database on costs

7. Value engineer the HE practice

8. Use the systems approach in design

9. Evaluate the trade-offs between air sealing, mechanical ventilation, and maintaining indoor air quality

10. Develop and evaluate multifunction technologies

11. Document indoor health impacts

12. Assess the public health and environmental impacts

13. Investigate the use of resource-efficient and environmentally benign building materials in rehab

14. Consider integrating energy features in the analysis of rehab options 


\section{REFERENCES}

Biederman, N., and J. Katrakis, 1989, Space Heating Improvements in Multifamily Buildings, Gas Research Institute, Chicago, Ill., Dec.

Diamond, R., et al., 1993, Chicago Affordable Housing Multifamily Building Rehab Study: Multizone Air Leakage Study, Interim Report, Lawrence Berkeley Laboratory, Energy Performance of Buildings Group, Berkeley, Calif., May.

Horn, P., 1994, "Poor Pinched to Pay Energy Bills this Winter as States, U.S. Cut Aid," Christian Science Monitor, Feb. 23, p. 6.

Katrakis, J., and L. Wharton, 1992, Energy Efficient Rehab Options for Low-Income Multifamily Buildings, presented by the Center for Neighborhood Technology, Chicago, Ill., at the Affordable Comfort Conference, March.

Katrakis, J., et al., 1992, Reducing Energy Costs for Low-Income Weatherization Clients - Phase II. Lighting and Refrigeration Testing Results, prepared by the Center for Neighborhood Technology, Chicago, Ill., for the Illinois Department of Energy and Natural Resources, Springfield, Ill., Dec.

Knight, P., 1994, Energy Efficient Affordable Housing Program - Multifamily Building Rehabilitation, Single Family New Home Construction, prepared by Domus Plus, Oak Park, Ill., for Illinois Department of Energy and Natural Resources, Springfield, Ill., Jan.

Lazere, E.B., et al., 1991, A Place to Call Home: The Low Income Housing Crisis Continues, Center on Budget and Policy Priorities, Washington, D.C., Dec.

Levine, A., et al., 1982, Energy Conservation in Rental Housing: Landlords' Perceptions of Problems and Solutions, SERI/RR-744-1308, Solar Energy Research Institute, Golden, Colo., March.

Lovins, A.B., 1992, Energy-Efficiency Buildings: Institutional Barriers and Opportunities, Strategic Issues Paper, E-Source, Boulder, Colo.

McCullom, B.; 1993, personal communication between McCullom (Architect, McCullom and Associates, Chicago, Ill.) and J. Katrakis (Decision and Information Sciences Division, Argonne National Laboratory), Dec. 29.

Wardell, C., 1993a, Journal of Light Construction 11(11):47. (Includes one example of a commercially available system for blowing cellulose dry into an open wall cavity: Dry Pac Wall System, by Parco, Inc., P.O. Box 1533, E. Hwy. 24, Norfolk, Neb., 68702; 800/288-0024.)

Wardell, C., 1993b, Journal of Light Construction 11(11):46. (Includes one example of commercially available foam-based fiber insulation: Fiberrific, 2191 S. Jason, Denver, Colo., 0223; 303-922-8277.) 